\title{
UHMWPE-Based Glass-Fiber Composites Fabricated by FDM. Multiscaling Aspects of Design, Manufacturing and Performance
}

\author{
Sergey V. Panin 1,2*(D), Dmitry G. Buslovich ${ }^{1,2} \mathbb{D}$, Yuri V. Dontsov ${ }^{1,2}$, Svetlana A. Bochkareva ${ }^{1}$, \\ Lyudmila A. Kornienko ${ }^{1}$ and Filippo Berto ${ }^{3}$
}

1 Laboratory of Mechanics of Polymer Composite Materials, Institute of Strength Physics and Materials Science SB RAS, 634055 Tomsk, Russia; buslovichdg@gmail.com (D.G.B.); doncov@mail2000.ru (Y.V.D.); svetlanab7@yandex.ru (S.A.B.); rosmc@ispms.ru (L.A.K.)

2 Department of Materials Science, Engineering School of Advanced Manufacturing Technologies, National Research Tomsk Polytechnic University, 634030 Tomsk, Russia

3 Department of Mechanical and Industrial Engineering, Faculty of Engineering, Norwegian University of Science and Technology (NTNU), 7491 Trondheim, Norway; filippo.berto@ntnu.no

* Correspondence: svp@ispms.ru; Tel.: +7-3822-286-904

check for updates

Citation: Panin, S.V.; Buslovich, D.G.; Dontsov, Y.V.; Bochkareva, S.A.; Kornienko, L.A.; Berto, F. UHMWPE-Based Glass-Fiber Composites Fabricated by FDM. Multiscaling Aspects of Design, Manufacturing and Performance. Materials 2021, 14, 1515. https:// doi.org/10.3390/ma14061515

Academic Editor: Andrea Bernasconi

Received: 20 February 2021

Accepted: 16 March 2021

Published: 19 March 2021

Publisher's Note: MDPI stays neutral with regard to jurisdictional claims in published maps and institutional affiliations.

Copyright: (c) 2021 by the authors. Licensee MDPI, Basel, Switzerland. This article is an open access article distributed under the terms and conditions of the Creative Commons Attribution (CC BY) license (https:/ / creativecommons.org/licenses/by/ $4.0 /)$.

\begin{abstract}
The aim of the paper was to improve the functional properties of composites based on ultra-high molecular weight polyethylene (UHMWPE) by loading with reinforcing fibers. It was achieved by designing the optimal composition for its subsequent use as a feedstock for 3D-printing of guides for roller and plate chains, conveyors, etc. As a result, it was experimentally determined that loading UHMWPE with 17\% high density polyethylene grafted with VinylTriMethoxySilane (HDPE-g-VTMS) was able to bind 5\% glass fillers of different aspect ratios, thereby determining the optimal mechanical and tribological properties of the composites. Further increasing the content of the glass fillers caused a deterioration in their tribological properties due to insufficient adhesion of the extrudable matrix due to the excessive filler loading. A multi-level approach was implemented to design the high-strength anti-friction 'UHMWPE+17\%HDPE-g-VTMS+12\%PP'-based composites using computer-aided algorithms. This resulted in the determination of the main parameters that provided their predefined mechanical and tribological properties and enabled the assessment of the possible load-speed conditions for their operation in friction units. The uniform distribution of the fillers in the matrix, the pattern of the formed supermolecular structure and, as a consequence, the mechanical and tribological properties of the composites were achieved by optimizing the values of the main control parameters (the number of processing passes in the extruder and the aspect ratio of the glass fillers).
\end{abstract}

Keywords: ultra-high molecular weight polyethylene; microfiller; compatibilizer; strength; wear resistance; supermolecular structure

\section{Introduction}

Ultra-high molecular weight polyethylene (UHMWPE) has numerous excellent characteristics including high impact strength, abrasion, and chemical resistance as well as biocompatibility [1-3]. Due to the high molecular weight of (3.5-7.5) $10^{6} \mathrm{~g} / \mathrm{mol}$, UHMWPE possesses a low melt flow index (MFI) of about zero, which makes it unsuitable for processing with conventional methods applied for polymers (screw extrusion, injection molding, and others) [4-6].

It is known that UHMWPE can be plasticized by loading with polypropylene (PP) [7-11], polyethylene glycol (PEG) [12-15], high density polyethylene (HDPE) [16-20], etc. Liu et al. [7] studied the morphology and properties of 'UHMWPE+PP'-based composites fabricated by the extrusion of mixtures using a single screw extruder. The microstructural analysis showed that PP was localized in both amorphous and low-crystalline zones of the 
UHMWPE matrix. At the same time, the UHMWPE fluidity increased significantly with enhancing the PP content. Xie et al. [12] significantly reduced the viscosity of melted UHMWPE by loading with PP and PEG. The mechanism of this effect was explained by untangling polymer chains. Lim et al. [18] investigated 'HDPE-UHMWPE' composites with different component ratios to determine their suitability as biomaterials. The presence of HDPE in the composites enabled a marked rise in MFI. In doing so, UHMWPE possessed improved toughness. The optimum conditions for mixing the feedstocks in the extruder were established. Kuang et al. [20] improved the UHMWPE's manufacturability by loading with poly(amido amine) dendrimer, and its derivatives with various end groups. Filling the UHMWPE matrix with dendritic modifiers resulted in a significant decrease in the melt viscosity, which allowed for an improvement in its processability.

Fibrous polymer composites are gaining widespread attention due to their low weight, high strength, and corrosion resistance. Loading with fibrous fillers enables the preservation of the original matrix characteristics and improve other operational properties [21-27]. The effects of loading with fiberglass (FG) and carbon fibers (CF) on the tribological properties of the UHMWPE-based composites was studied in [26]. The FG content of 10\% was the optimal level to effectively reduce the wear rate and the friction coefficient of the composites. Chukov et al. [27] investigated UHMWPE-based composites containing chopped $\mathrm{CF}$ in amounts of up to $12 \%$. Annealing (in air at a temperature of $500^{\circ} \mathrm{C}$ ) resulted in a defect structure formation on the CF surfaces. Consequently, the activity of the latter was increased. Thus, GF and CF are common fillers for UHMWPE in order to obtain high-strength wear-resistant composites fabricated by compression sintering.

It is known that in addition to the matrix characteristics, the mechanical properties of fiber-reinforced polymer composites mainly depend on: (i) the loading degree, (ii) the physical and mechanical attributes of fibers, and (iii) the morphology, activity, and area of their surfaces, which determine the interfacial bonding between the fibers and the matrix [28-30]. Since FG are characterized by low interfacial adhesion with UHMWPE, the aim of research is (typically) to improve this parameter through various methods [31,32]. In particular, the issue can be solved by treatment of the FG surfaces with a silane coupling agent [33]. Composites reinforced with treated GF have shown better mechanical properties (tensile strength and impact toughness) than ones loaded with untreated fillers [34]. For instance, low density polyethylene (LDPE) chemically modified with vinyltriethoxy lane (VTES) has been used (as a coupling agent) to reinforce the UHMWPE-based composites loaded with GF [35]. As a result, they were characterized by more elastic and less ductile behavior.

However, as a rule, some key issues remain outside the scope of discussions. They include: (a) the effect of a technological sizing agent applied to improve the FG dispersibility (the presence of which does not contribute to an increase in adhesion to the polymer matrix); and (b) variations of this parameter upon manufacturing of the composites by powder methods (in this case, the nature of the filler distributions is largely limited by the arrangement of the components at the 'mixing in suspension' stage), etc. For this reason, alternative methods should be applied to prepare feedstocks from polymer powders and FG (for example, using a twin-screw extruder [36,37]), which enables the ability to thoroughly stir them in the molten state.

In the current study, powder mixtures were compounded in a twin-screw extruder. Then, samples were fabricated by hot compression (HC) and 3D printing (more precisely, by the fused deposition modeling (FDM)) methods using the milled granulate as a feedstock. Due to the almost zero MFI of molten UHMWPE, an additional ' $17 \%$ HDPE-g-VTMS+12 $\% \mathrm{PP}^{\prime}$ plasticizing component was loaded (hereinafter, the percentages are by weight). For the deployed twin-screw extruder, the polymer mixing parameters have already been optimized in previous studies by the authors [38]. Thus, the main difference between this paper and others devoted to the UHMWPE-based glass-fiber composites is the design of an improved one manufactured by 3D printing, which possesses high tribological and mechanical properties. 
In addition, the role of compatibilizers (grafted HDPE in the studied case) should be noted, which are typically used to combine various polymers $[39,40]$. Loading the composites with HDPE-g-VTMS aims to provide a chemical bond between HDPE, UHMWPE, and the FG filler. According to the authors' idea, compounding the components in the twin-screw extruder should have ensured the maximum dispersion degree for the HDPEg-VTMS powder characterized by coarse particles.

Nevertheless, design of the high-strength 'UHMWPE+17\%HDPE-g-VTMS+12\%PP'based composites, fabricated by extrusion and $3 \mathrm{D}$ printing, is required to expand areas of their applications.

In [41], extrudable UHMWPE-based composites were designed, which were loaded with 30\% HDPE modified with 5-10\% organo-montmorillonite (OMMT). They possessed high thermal and mechanical properties for the manufacturing of pipes by screw extrusion. The effect of the HDPE-g-SMA compatibilizer and the $\gamma$-(2,3-epoxy-propoxy) propyltrimethoxysilane (KH560) silane coupling agent in an amount of $3 \%$ on the thermal properties of the UHMWPE-based pipes was investigated. It was found that loading with OMMT significantly improved the properties compared to those for pipes made of neat UHMWPE.

In these studies, the task was to improve the functional properties of the UHMWPEbased composites by loading with reinforcing fibers, but in one technological cycle (procedure), considering the features of processing UHMWPE by conventional (screw extrusion) or advanced (FDM) methods. Their manufacturability and characteristics should be at the neat UHMWPE levels. The authors deliberately chose milled and chopped FG fillers for the following reasons:

1. FG is common low-cost industrial filler, characterized by high technological effectiveness;

2. FG have a stable composition, shapes and the aspect ratio, which enables to reliably compare the effect of micron- and millimeter-scale fiber sizes;

3. Loading with commercially available HDPE-g-VTMS allows for an increase in interfacial adhesion with FG filler, which improves the physical and mechanical properties of the composites.

The goal was to design the optimal composition for its subsequent use as a feedstock for 3D printing of guides for roller and plate chains, conveyors, etc.

The remainder of this paper is structured as follows. Section 2 describes the methodological aspects of research related to the specifics of preparation and testing of samples. In Section 3, a comparison of the physical, mechanical and tribological properties is reported for the 'UHMWPE+17\%HDPE-g-VTMS+12\%PP'-based composites loaded with GF of various sizes and fabricated by hot compression ( $\mathrm{HC}$ ) of powder mixtures and granules after twin-screw compounding (TSC). The final part of the third experimental section presents the results of the mechanical and tribological tests (under various load-speed conditions) of the extrudable UHMWPE-based composites fabricated by HC of the powders and granules as well as by 3D printing. In Section 4, the requirements for the composites are substantiated on the assumption of their application for guide manufacturing. These suggestions are based on the experimental results and the characteristics provided by manufacturers of the UHMWPE-based materials. In Section 5, values of the control parameters are reported, which are based on the obtained experimental data and the developed computer-aided algorithm to justify the recommendations (the number of processing passes and the aspect ratio of the GF fillers) for the manufacturing of 'UHMWPE+17\%HDPE-g-VTMS+12\%PP'-based composites with the predefined mechanical and tribological properties.

\section{Materials and Methods}

2.1. Fabrication of the Ultra-High Molecular Weight Polyethylene (UHMWPE)-Based Composites

'Ticona GUR-2122' UHMWPE powder (Celanese Corporation, Irving, TX, USA) was used to fabricate samples. Its molecular weight was about 4.5 million. Particle sizes were 5-15 $\mu \mathrm{m}$, which were weakly agglomerated into aggregates with sizes of 120-150 $\mu \mathrm{m}$ (Figure 1a). The 'Olenten' HDPE-g-VTMS (Figure 1b) was loaded as a compatibilizer (New 
Polymer Technologies LLC, Moscow, Russia). It was purchased in the form of granules 2-3 $\mu \mathrm{m}$ in size. Then, HDPE-g-VTMS was mechanically milled using a 'Rondol' chopper (Rondol, France) to a particle size of $\sim 525 \mu \mathrm{m}$. The 'PP 21030' (TomskNefteChim LLC, Tomsk, Russia) particle sizes were also about $525 \mu \mathrm{m}$ (Figure 1c). Its MFI was $3.0 \mathrm{~g} / 10 \mathrm{~min}$ $(2.1 \mathrm{~kg}$ ). Data on GF fillers (Figure 1d-f) are presented in Table 1.

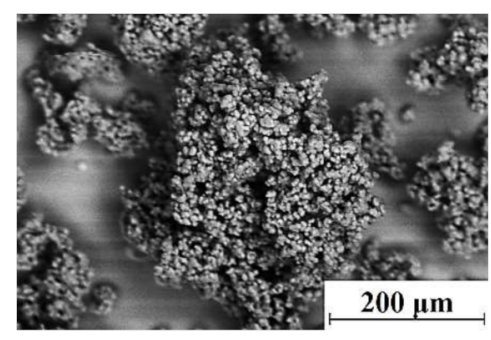

(a)

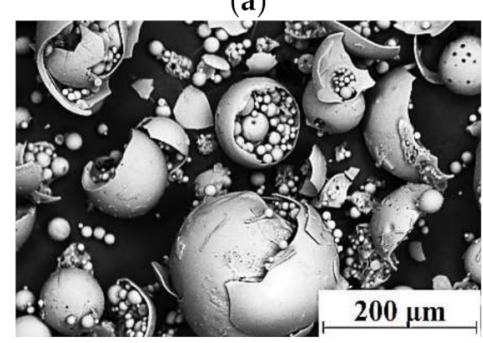

(d)

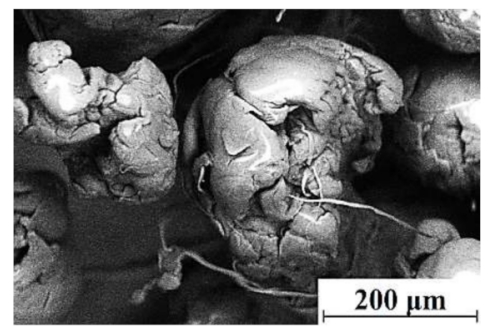

(b)

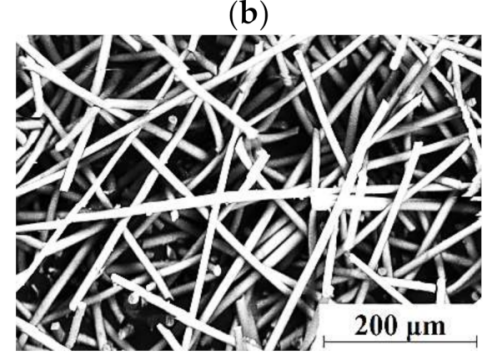

(e)

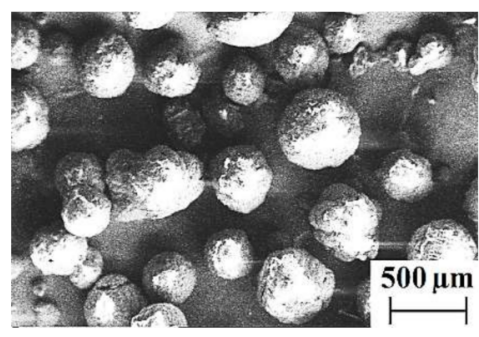

(c)

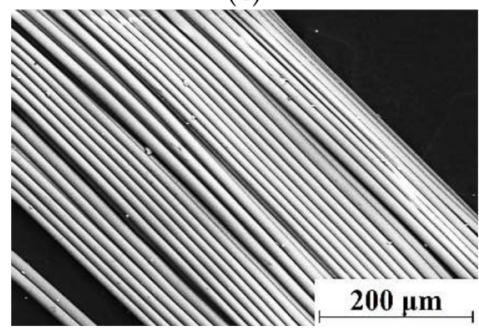

(f)

Figure 1. Scanning electron microscopy (SEM) micrographs of the materials: (a) Ultra-high molecular weight polyethylene (UHMWPE); (b) high density polyethylene grafted with VinylTriMethoxySilane (HDPE-g-VTMS); (c) polypropylene (PP);

(d) hollow glass spheres (HGS); (e) milled glass fibers (MGF); (f) chopped glass fiber (CGF).

Table 1. The fillers used for the fabrication of the composites.

\begin{tabular}{ccccc}
\hline Type & Mean Length $(\mu \mathrm{m})$ & Diameter $(\mu \mathrm{m})$ & The Aspect Ratio & Supplier \\
\hline Hollow glass spheres (HGS) & $15-200$ & $15-200$ & 1 & $\begin{array}{c}\text { 3M, Saint Paul, MN, USA } \\
\text { Jushi Group Co. Ltd. Tonaxina } \\
\text { Economic Development Zone, } \\
\text { Zhejiang, China }\end{array}$ \\
Milled glass spheres (MGF) & 200 & $9-14$ & 20 & $\begin{array}{c}\text { Jushi Group Co. Ltd. Tonaxina } \\
\text { Economic Development Zone, } \\
\text { Zhejiang, China }\end{array}$ \\
\hline
\end{tabular}

The powders and the GF fillers were mixed by dispersing the suspension in alcohol using a 'PSB-Gals 1335-05' ultrasonic cleaner ('PSB-Gals' Ultrasonic equipment center, Moscow, Russia). The processing duration was $3 \mathrm{~min}$; the generator frequency was $22 \mathrm{kHz}$. After mixing, the suspension was dried in a 'Memmert UF 55' oven (Binder, Tutlingen, Germany) using forced ventilation at a temperature of $120^{\circ} \mathrm{C}$ for $3 \mathrm{~h}$.

For the purpose of homogeneous mixing of small UHMWPE particles (tens of microns in size) with large ones of the polymer fillers (hundreds of microns) for 3D-printing, they were compounded in the 'Rondol' twin-screw extruder. Furthermore, bulk preforms of the composites were fabricated in the following ways:

1. By $\mathrm{HC}$ of the multi-component powder mixtures (referred to as 'HC-PM' in the paper) at a pressure of $10 \mathrm{MPa}$ and a temperature of $200{ }^{\circ} \mathrm{C}$ using a laboratory setup based on a 'MS-500' hydraulic press (NPK TekhMash LLC, Moscow, Russia). The setup was equipped with an open-loop ring furnace with a digital temperature controller (ITM LLC, Tomsk, Russia). After exposing under pressure, the preforms were cooled without unloading for $30 \mathrm{~min}$. Cooling rate was $5^{\circ} \mathrm{C} / \mathrm{min}$. 
2. By HC of granules of the multi-component mixtures compounded by the Twin-Screw Extruder (referred to as 'HC-TSE' hereinafter). The same facilities and the parameters were applied as in the HC-PM procedure.

3. By FDM from granules of the same polymer components (referred to as 'FDM-TSE') using an 'ArmPrint-2' laboratory (craft) 3D-printer (NR TPU, Tomsk, Russia) equipped with a single-screw micro-extruder (a nozzle diameter of $0.4 \mathrm{~mm}$ ). It was developed and deployed for printing with granules of $2-5 \mathrm{~mm}$ in size. A print head moved in three $X Y Z$ coordinates. The amount of the fed material was determined by the microscrew rotational speed. The 3D-printer was equipped with a heated bed operated in a temperature range of $50-300{ }^{\circ} \mathrm{C}$. The material temperature in the micro-extruder could be varied within $150-420^{\circ} \mathrm{C}$. The process was controlled by the 'LINUX CNC' operating system. Printing was carried out according to the model prepared in the 'G-code' format. Digital model files were created using 'Repetir-Host V2.1.3' software (Hot-World GmbH KG Knickelsdorf 4247877 Willich Germany) and 'Slic3r' slicer (licensed under the GNU Affero General Public License, version 3). Temperatures of the bed as well as the upper and lower regions of a filament (granules) feeder were constant at 90,160 , and $200{ }^{\circ} \mathrm{C}$, respectively. Each deposited layer was $0.3 \mathrm{~mm}$ thick.

\subsection{Examination of the Physical and Mechanical Properties}

The Shore D hardness was determined using an "Instron 902" facility (Instron, Norwood, MA, USA) in accordance with ASTM D 2240. Tensile properties of 'dog-bone' shaped specimens were assessed using an 'Instron 5582' electromechanical testing machine (Instron, Norwood, MA, USA). The number of each type specimen was at least four.

\subsection{Assessment of the Tribological Characteristics}

Wear resistance was evaluated according to the 'block-on-ring' scheme using a '2070 SMT-1' friction testing machine (Tochpribor Production Association, Ivanovo, Russia). Loads $(\mathrm{P})$ on the samples were 60 and $140 \mathrm{~N}$ (contact pressures $P_{\max }$ of 9.7 and $32.4 \mathrm{MPa}$, respectively). Sliding speeds $(\mathrm{V})$ were 0.3 and $0.5 \mathrm{~m} / \mathrm{s}$. The P.V combinations of $60 \mathrm{~N} \cdot 0.3 \mathrm{~m} / \mathrm{s}$ and $140 \mathrm{~N} \cdot 0.5 \mathrm{~m} / \mathrm{s}$ were designated hereinafter as the 'mild' and 'severe' tribological conditions, respectively. A disk-shaped counterpart was made of the outer ring of a commercial bear. Its diameter was $35 \mathrm{~mm}$ and width was $11 \mathrm{~mm}$. The counterpart surface roughness was $0.20-0.25 \mu \mathrm{m}$. The counterpart temperature was measured using a 'CEM DT-820' non-contact InfraRed (IR) thermometer (Shenzhen Everbest Machinery Industry Co. Ltd., Shenzhen, China). Wear rates were determined by measuring the width and depth of the wear track according to stylus profilometry, followed by multiplication by its length. Wear rates were calculated considering the load and sliding distance values:

$$
\text { Wear rate }=\frac{\text { volume loss }\left(\mathrm{mm}^{3}\right)}{\text { load }(\mathrm{N}) \times \text { sliding distance }(\mathrm{m})}
$$

The wear track profiles were assessed using the data on at least ten tracks. Then, wear rates were estimated on the basis of the experimental results over at least four samples of each type. Mathematical statistics methods were applied for data processing.

\subsection{Structural Studies}

The topography of the wear track surfaces was investigated using a 'Neophot 2' optical microscope (Carl Zeiss, Oberkochen, Germany) equipped with a 'Canon EOS 550D' digital camera (Canon Inc., Tokyo, Japan), and an 'Alpha-Step IQ' stylus profiler (KLA-Tencor, Milpitas, CA, USA).

Initially, the notched polymer samples were cooled in liquid nitrogen at $-197^{\circ} \mathrm{C}$ for one hour, and then mechanically fractured. The cleaved surfaces were used to study the filler distribution as well as the supermolecular structure. In vacuum, copper films about $10 \mathrm{~nm}$ thick were deposited on the fracture surfaces using a 'JEOL JEE-420' vacuum evaporator (JEOL USA, Inc., Peabody, MA, USA). The requirements for the thickness of 
the conductive film were dictated by the need to preserve the morphology of the original fracture surfaces. A 'LEO EVO 50' scanning electron microscope (Carl Zeiss, Oberkochen, Germany) was employed at an accelerating voltage of $20 \mathrm{kV}$.

\section{Results and Discussion}

\subsection{The Glass Powder (Hollow Glass Spheres)}

In these studies, the glass powder was loaded not with the aim of improving the physical, mechanical, and tribological properties of the 'UHMWPE+17\%HDPE-g-VTMS+12\%PP'based composites, but as a 'zero' point, namely as a filler with the aspect ratio of 1 . This was due to the facts that (i) the powder particles were too different in sizes; (ii) they were hollow and, therefore, damaged upon the mixture extrusion; and (iii) the distribution of the HGS fragments as well as size dispersion were uneven.

Table 2 presents the mechanical properties of the 'UHMWPE+17\%HDPE-g-VTMS+12\%PP'based composites fabricated by the HC-PM and HC-TSE methods at HGS loading from 2.5 to $10.0 \%$.

Table 2. The mechanical properties of neat UHMWPE and the 'UHMWPE+17\%HDPE-g-VTMS+12\%PP'-based composites loaded with hollow glass spheres (HGS).

\begin{tabular}{|c|c|c|c|c|c|}
\hline $\begin{array}{l}\text { Filler Composition } \\
\text { (wt. \%) }\end{array}$ & Density $\rho\left(\mathrm{g} / \mathrm{cm}^{3}\right)$ & Shore D Hardness & $\begin{array}{c}\text { Young's Modulus } \\
\text { G (MPa) }\end{array}$ & $\begin{array}{c}\text { Yield Strength } \\
\sigma_{Y}(\mathrm{MPa})\end{array}$ & $\begin{array}{c}\text { Tensile Strength } \\
\sigma_{\mathrm{T}}(\mathrm{MPa})\end{array}$ \\
\hline None & 0.934 & $57.7 \pm 0.6$ & $711 \pm 40$ & $21.6 \pm 0.6$ & $42.9 \pm 3.1$ \\
\hline \multicolumn{6}{|c|}{ Powder/Granules } \\
\hline $\begin{array}{l}\text { 17\%HDPE-g- } \\
\text { VTMS+12\%PP }\end{array}$ & $\begin{array}{c}0.933 / \\
0.939\end{array}$ & $\begin{array}{c}57.8 \pm 0.3 / \\
59.1 \pm 0.2\end{array}$ & $\begin{array}{l}876 \pm 71 / \\
907 \pm 75\end{array}$ & $\begin{array}{c}25.1 \pm 0.3 / \\
26.8 \pm 0.6\end{array}$ & $\begin{array}{c}19.1 \pm 1.3 / \\
34.3 \pm 2.7\end{array}$ \\
\hline$+2.5 \%$ HGS & $\begin{array}{l}0.961 / \\
0.950\end{array}$ & $\begin{array}{c}58.2 \pm 0.7 / \\
58.5 \pm 0.3\end{array}$ & $\begin{array}{l}781 \pm 23 / \\
1092 \pm 28\end{array}$ & $\begin{array}{c}23.2 \pm 0.5 / \\
24.8 \pm 0.3\end{array}$ & $\begin{array}{l}19.1 \pm 0.4 / \\
21.2 \pm 1.6\end{array}$ \\
\hline$+5.0 \%$ HGS & $\begin{array}{l}0.972 / \\
0.965\end{array}$ & $\begin{array}{c}58.1 \pm 0.5 / \\
58.2 \pm 0.3\end{array}$ & $\begin{array}{l}872 \pm 72 / \\
1131 \pm 39\end{array}$ & $\begin{array}{c}23.2 \pm 0.4 / \\
24.6 \pm 0.1\end{array}$ & $\begin{array}{l}18.4 \pm 1.5 / \\
27.6 \pm 0.5\end{array}$ \\
\hline$+7.5 \%$ HGS & $\begin{array}{l}0.983 / \\
0.980\end{array}$ & $\begin{array}{c}58.2 \pm 0.4 / \\
58.8 \pm 0.3\end{array}$ & $\begin{array}{l}909 \pm 52 / \\
1127 \pm 54\end{array}$ & $\begin{array}{c}23.1 \pm 0.9 / \\
24.6 \pm 0.4\end{array}$ & $\begin{array}{c}21.6 \pm 1.4 / \\
26.4 \pm 1.6\end{array}$ \\
\hline$+10.0 \%$ HGS & $\begin{array}{l}0.993 / \\
1.003\end{array}$ & $\begin{array}{l}58.1 \pm 0.5 / \\
58.7 \pm 0.2\end{array}$ & $\begin{array}{l}859 \pm 82 / \\
1134 \pm 85\end{array}$ & $\begin{array}{l}22.1 \pm 0.7 / \\
23.9 \pm 2.2\end{array}$ & $\begin{array}{c}18.2 \pm 0.3 / \\
24.9 \pm 3.9\end{array}$ \\
\hline
\end{tabular}

Neat UHMWPE was characterized by high elongation at break values (about $485 \%$ depending on the fabrication method). During the tests, the samples were lengthened, which was accompanied by strengthening due to the predominant orientation of polymer chains. As a result, the tensile strength values were almost twice the yield strength levels. Loading UHMWPE with GF improved yield strength, especially under conditions of increased interphase adhesion. However, GF fractures during the tests caused the entire composite failures. Thus, the decrease in tensile strength was due to the small contribution of the polymer matrix to hardening. The uniform filler distribution in the matrix upon twin-screw compounding did improve tensile strength.

It follows from Table 2 that the mechanical properties (Young's modulus and ultimate tensile strength) of the HC-PM composites were 1.3-1.5 times lower than those for the HC-TSE ones. Figure 2 shows the SEM micrographs of the supermolecular structure of the 'UHMWPE+17\%HDPE-g-VTMS+12\%PP'-based composites fabricated by the HC-PM and HC-TSE methods. The supermolecular structures of the composites fabricated by the HC-TSE procedure were fundamentally different from the HC-PM ones. The GF filler was more evenly distributed in the HC-TSE matrices. Twin-screw compounding of the multicomponent polymer mixtures with different sizes of the initial components formed the homogeneous supermolecular structures of the composites (Figure $2 \mathrm{~b}, \mathrm{~d}$ ), which provided their higher mechanical properties (Table 2). 


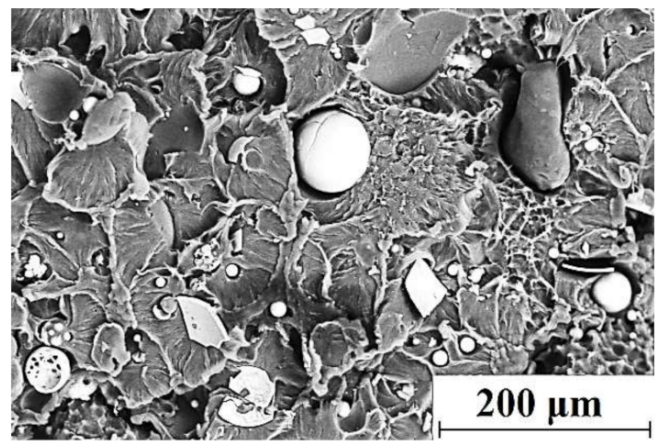

(a)

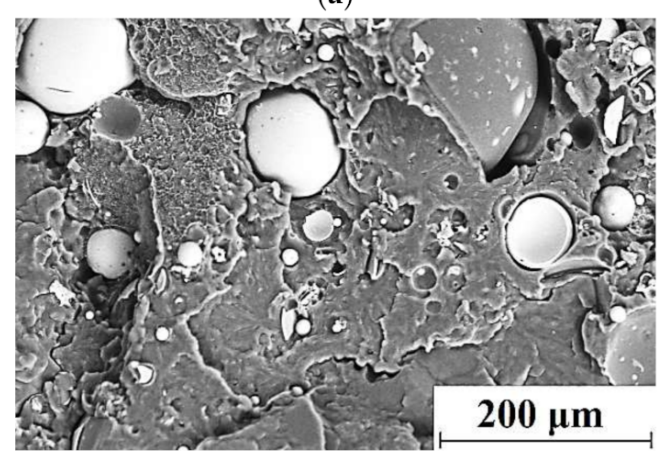

(c)

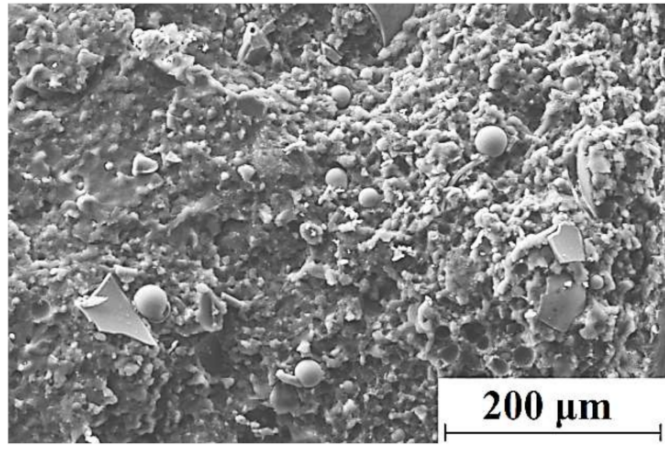

(b)

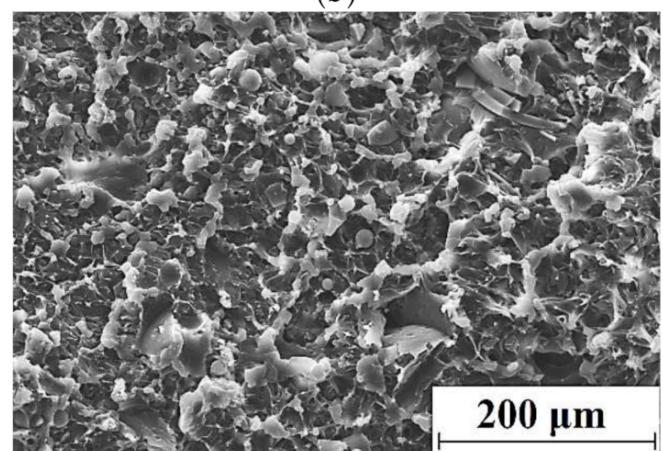

(d)

Figure 2. The scanning electron microscopy (SEM) micrographs of the supermolecular structure of the 'UHMWPE $+17 \%$ HDPE-g-VTMS+12\%PP+5\%HGS' (a,b) and 'UHMWPE+17\%HDPE-g-VTMS+12\%PP+10\%HGS' (c,d); HC-PM (a,c), hot compression by the Twin-Screw Extruder (HC-TSE) (b,d).

It is known that the mechanical and tribological properties were not always unambiguously correlated with each other. For this reason, the tribological characteristics of the HC-PM composites were also evaluated (despite their physical and mechanical properties were markedly lower). Figure 3 shows the wear rates and the friction coefficients for the 'UHMWPE+17\% HDPE-g-VTMS+12\% PP'-based composites, fabricated by the HC-PM and HC-TSE methods, under the dry friction conditions according to the 'pin-on-disk' and 'block-on-ring' schemes. The friction coefficients were weakly dependent on both filler contents and fabrication methods. Thus, the results of the tribological tests should be interpreted not only on the basis of their structures and the mechanical properties.

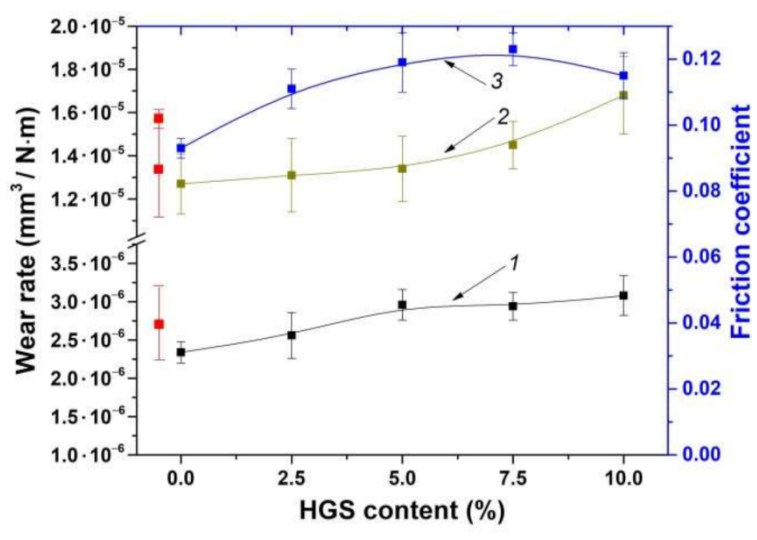

(a)

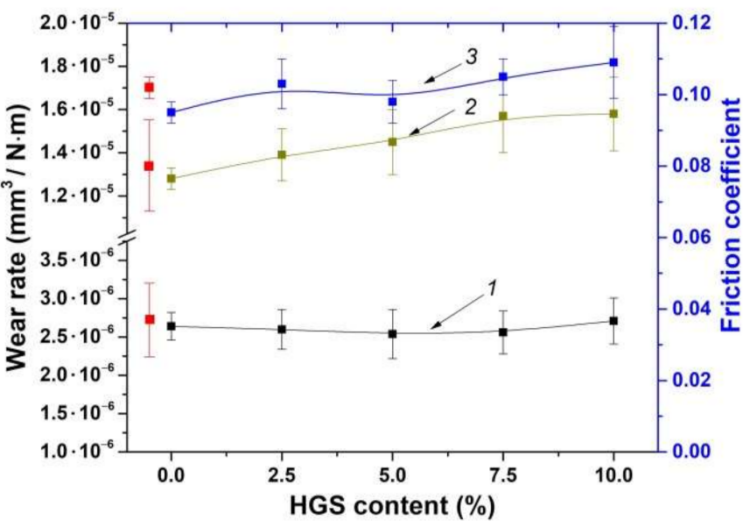

(b)

Figure 3. Wear rates according to the 'pin-on-disk' (curve 1, $5 \mathrm{~N} \cdot 0.3 \mathrm{~m} / \mathrm{s}$ ) and 'block-on-ring' (curve 2, $60 \mathrm{~N} \cdot 0.3 \mathrm{~m} / \mathrm{s}$ ) schemes as well as the average friction coefficients (curve 3) versus filler weight fraction: HC-PM (a), HC-TSE (b). 
As follows from Figure 3 (curves 1 and 3), wear rates were slightly enhanced with an increase in the HGS content. With regard to wear rates and the friction coefficient of the HC-TSE composites, almost unchanged linear trends could be observed with an increase in the filler contents.

Figure 3 (curve 2) illustrates the wear rates of neat UHMWPE and the 'UHMWPE $+17 \%$ HDPE-g-VTMS+12\%PP'-based composites under the 'mild' tribological conditions according to the 'block-on-ring' scheme. Wear rates were slightly raised with the increase in the HGS content. Nevertheless, the dynamics for both HC-PM and HC-TSE composites were comparable in this case. The authors suggested that gradual wear rate enhancing for the composites substantially loaded with HGS (7.5-10\%) was associated with the abrasive wear of the counterpart and its subsequent destructive effect on the surfaces of the tribological contact parts.

Thus, very heterogeneous composites had been formed by the HC-PM procedure, which could not possess high physical, mechanical, and tribological properties. However, it was possible to evenly disperse the fillers in the UHMWPE matrix by the HC-TSE method, thereby increasing the strength properties and maintaining the tribological characteristics at the neat UHMWPE level.

\subsection{Milled Glass Fibers (200 $\mu \mathrm{m}$ in Length)}

Table 3 presents the mechanical properties of neat UHMWPE and the 'UHMWPE $+17 \%$ HDPE-g-VTMS+12\% PP'-based composites loaded with 2.5 to $10.0 \%$ MGF (the aspect ratio of 20) and fabricated by the HC-PM and HC-TSE methods.

Table 3. The mechanical properties of neat UHMWPE and the 'UHMWPE+17\% HDPE-g-VTMS+12\% PP'-based composites loaded with MGF (200 $\mu \mathrm{m}$ in length).

\begin{tabular}{|c|c|c|c|c|c|}
\hline $\begin{array}{l}\text { Filler Composition } \\
\text { (wt.\%) }\end{array}$ & Density $\rho\left(\mathrm{g} / \mathrm{cm}^{3}\right)$ & $\begin{array}{l}\text { Shore D } \\
\text { Hardness }\end{array}$ & $\begin{array}{l}\text { Young's Modulus } \\
\text { G (MPa) }\end{array}$ & $\begin{array}{l}\text { Yield Strength } \sigma_{Y} \\
(\mathrm{MPa})\end{array}$ & $\begin{array}{c}\text { Tensile Strength } \\
\sigma_{\mathrm{T}}(\mathrm{MPa})\end{array}$ \\
\hline None & 0.934 & $57.7 \pm 0.6$ & $711 \pm 40$ & $21.6 \pm 0.6$ & $42.9 \pm 3.1$ \\
\hline \multicolumn{6}{|c|}{ Powder/Granules } \\
\hline $\begin{array}{l}\text { 17\%HDPE-g- } \\
\text { VTMS+12\%PP }\end{array}$ & $\begin{array}{l}0.933 / \\
0.939\end{array}$ & $\begin{array}{l}57.8 \pm 0.3 / \\
59.1 \pm 0.2\end{array}$ & $\begin{array}{l}876 \pm 71 / \\
907 \pm 75\end{array}$ & $\begin{array}{l}25.1 \pm 0.3 / \\
26.8 \pm 0.6\end{array}$ & $\begin{array}{l}19.1 \pm 1.3 / \\
34.3 \pm 2.7\end{array}$ \\
\hline$+2.5 \% \mathrm{MGF}$ & $\begin{array}{l}0.951 / \\
0.959\end{array}$ & $\begin{array}{l}60.8 \pm 0.5 / \\
58.6 \pm 0.2\end{array}$ & $\begin{array}{l}984 \pm 82 / \\
1019 \pm 38\end{array}$ & $\begin{array}{c}24.8 \pm 0.7 / \\
25.9 \pm 0.8\end{array}$ & $\begin{array}{c}20.2 \pm 0.8 / \\
21.5 \pm 2.2\end{array}$ \\
\hline$+5.0 \% \mathrm{MGF}$ & $\begin{array}{l}0.947 / \\
0.945\end{array}$ & $\begin{array}{c}59.9 \pm 0.6 / \\
60.4 \pm 0.6\end{array}$ & $\begin{array}{l}1063 \pm 65 / \\
1153 \pm 66\end{array}$ & $\begin{array}{c}24.1 \pm 1.9 / \\
26.5 \pm 0.9\end{array}$ & $\begin{array}{c}19.9 \pm 0.5 / \\
25.3 \pm 3.2\end{array}$ \\
\hline$+7.5 \% \mathrm{MGF}$ & $\begin{array}{l}0.978 / \\
0.972\end{array}$ & $\begin{array}{l}60.8 \pm 1.1 / \\
59.7 \pm 0.2\end{array}$ & $\begin{array}{l}1072 \pm 55 / \\
1148 \pm 87\end{array}$ & $\begin{array}{l}25.3 \pm 0.5 / \\
26.6 \pm 0.5\end{array}$ & $\begin{array}{c}20.6 \pm 0.9 / \\
23.5 \pm 1.6\end{array}$ \\
\hline$+10.0 \% \mathrm{MGF}$ & $\begin{array}{l}1.006 / \\
1.008\end{array}$ & $\begin{array}{l}59.5 \pm 0.7 / \\
59.4 \pm 0.4\end{array}$ & $\begin{array}{l}1101 \pm 79 / \\
1155 \pm 28\end{array}$ & $\begin{array}{c}25.5 \pm 0.6 / \\
26.7 \pm 0.9\end{array}$ & $\begin{array}{c}20.5 \pm 1.3 / \\
22.3 \pm 1.4\end{array}$ \\
\hline
\end{tabular}

It follows from Table 3 that loading with MGF into the 'UHMWPE+17\% HDPE-gVTMS $+12 \% \mathrm{PP}^{\prime}$ matrix increased the Young's modulus by 1.3-1.6 times compared to that for neat UHMWPE. Yield strength varied slightly with an increase in the MGF contents for the composites fabricated by both HC-PM and HC-TSE methods. Ultimate tensile strength of the HC-TSE composite loaded with 5\% MGF was 1.3 times higher than that of the HC-PM one.

Figure 4 shows the friction coefficients and wear rates of the composites loaded with various MGF contents and fabricated by the HC-PM and HC-TSE methods.

It can be concluded that the wear rates of the composites fabricated by both procedures decreased with an increase in the MGF content up to $5 \%$, and then enhanced for the HC-TSE samples. However, they did not change in the case of the HC-PM ones. Dependences in the friction coefficients from the MGF contents were similar. According to the authors, the increase in wear rate of the composites loaded with MGF was due to the imposition of the cutting action of the rough counterpart surface and the microabrasive effect of the hard FG debris. 


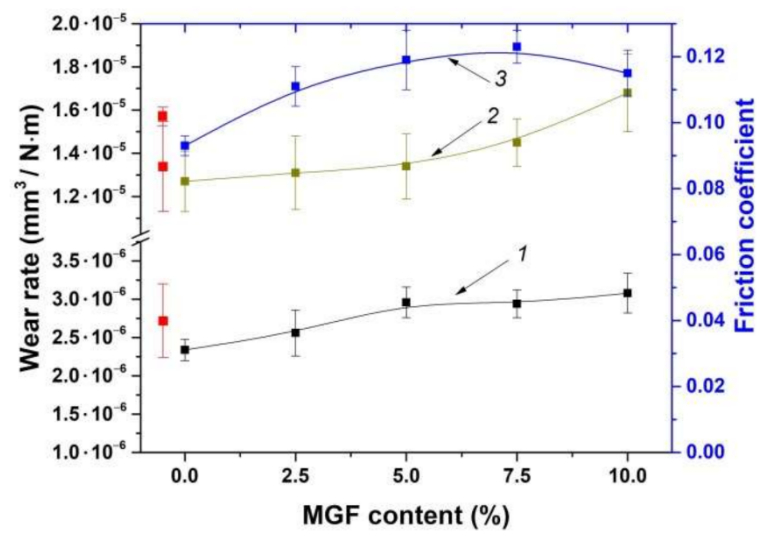

(a)

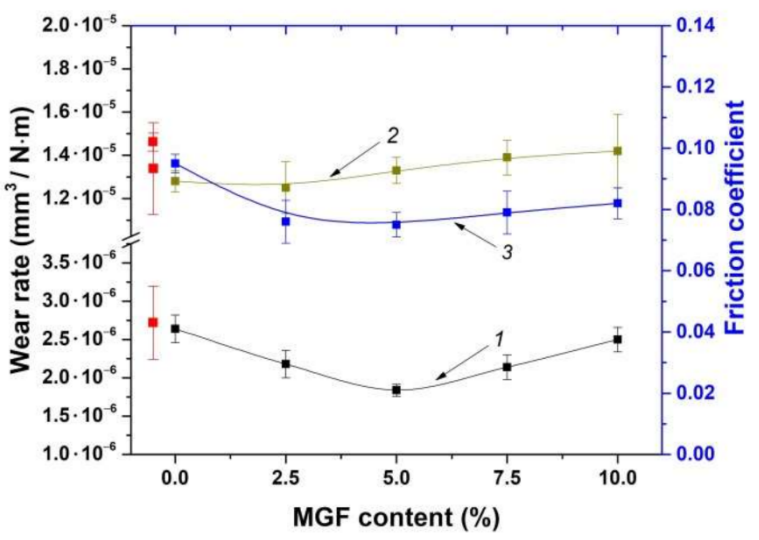

(b)

Figure 4. Wear rates according to the 'pin-on-disk' (curve 1, $5 \mathrm{~N} \cdot 0.3 \mathrm{~m} / \mathrm{s}$ ) and 'block-on-ring' (curve 2, 60 N.0.3 m/s) schemes as well as the average friction coefficients (curve 3) versus filler weight fraction: HC-PM (a), HC-TSE (b).

Figure 4 (curve 2) shows the wear rates of the composites according to the 'blockon-ring' scheme under the 'mild' tribological conditions. The values enhanced with an increase in the MGF contents for the HC-PM composites. For the HC-TSE samples, wear rates were less than that for neat UHMWPE. In addition, they were at approximately the same level regardless of the MGF contents.

\subsection{Chopped Glass Fibers ( $3 \mathrm{~mm}$ in Length)}

Table 4 presents the mechanical properties of the 'UHMWPE+17\%HDPE-g-VTMS+12\%PP'based composites fabricated by the HC-PM and HC-TSE methods at CGF loading of 2.5 to $10.0 \%$ (the aspect ratio of 300 ).

Table 4. The mechanical properties of neat UHMWPE and the 'UHMWPE+17\%HDPE-g-VTMS+12\%PP'-based composites loaded with CGF (3 $\mathrm{mm}$ in length).

\begin{tabular}{|c|c|c|c|c|c|}
\hline $\begin{array}{l}\text { Filler Composition } \\
\text { (wt.\%) }\end{array}$ & Density $\rho\left(\mathrm{g} / \mathrm{cm}^{3}\right)$ & Shore D Hardness & $\begin{array}{c}\text { Young's Modulus } \\
\text { G (MPa) }\end{array}$ & $\begin{array}{l}\text { Yield Strength } \sigma_{Y} \\
(\mathrm{MPa})\end{array}$ & $\begin{array}{c}\text { Tensile Strength } \\
\sigma_{\mathrm{T}}(\mathrm{MPa})\end{array}$ \\
\hline None & 0.934 & $57.7 \pm 0.6$ & $711 \pm 40$ & $21.6 \pm 0.6$ & $42.9 \pm 3.1$ \\
\hline \multicolumn{6}{|c|}{ Powder/Granules } \\
\hline $\begin{array}{l}\text { 17\%HDPE-g- } \\
\text { VTMS+12\%PP }\end{array}$ & $\begin{array}{c}0.933 / \\
0.939\end{array}$ & $\begin{array}{l}57.8 \pm 0.3 / \\
59.1 \pm 0.2\end{array}$ & $\begin{array}{l}876 \pm 71 / \\
907 \pm 75\end{array}$ & $\begin{array}{l}25.1 \pm 0.3 / \\
26.8 \pm 0.6\end{array}$ & $\begin{array}{l}19.1 \pm 1.3 / \\
34.3 \pm 2.7\end{array}$ \\
\hline$+2.5 \%$ CGF & $\begin{array}{l}0.979 / \\
0.964\end{array}$ & $\begin{array}{c}57.9 \pm 0.6 / \\
57.9 \pm 0.3\end{array}$ & $\begin{array}{l}1031 \pm 50 / \\
1148 \pm 67\end{array}$ & $\begin{array}{l}20.9 \pm 0.8 / \\
25.7 \pm 0.5\end{array}$ & $\begin{array}{c}18.3 \pm 1.1 / \\
22.7 \pm 1.7\end{array}$ \\
\hline$+5.0 \%$ CGF & $\begin{array}{c}0.984 / \\
0.972\end{array}$ & $\begin{array}{c}58.4 \pm 0.4 / \\
58.9 \pm 0.4\end{array}$ & $\begin{array}{l}1208 \pm 45 / \\
1241 \pm 45\end{array}$ & $\begin{array}{l}23.3 \pm 0.9 / \\
25.2 \pm 0.4\end{array}$ & $\begin{array}{l}19.2 \pm 1.5 / \\
25.2 \pm 1.5\end{array}$ \\
\hline$+7.5 \% \mathrm{CGF}$ & $\begin{array}{l}1.009 / \\
0.999\end{array}$ & $\begin{array}{c}58.4 \pm 0.7 / \\
59.2 \pm 0.4\end{array}$ & $\begin{array}{l}1172 \pm 21 / \\
1261 \pm 50\end{array}$ & $\begin{array}{c}24.1 \pm 0.3 / \\
25.2 \pm 0.3\end{array}$ & $\begin{array}{l}18.9 \pm 0.6 / \\
23.2 \pm 3.1\end{array}$ \\
\hline$+10.0 \%$ CGF & $\begin{array}{l}1.034 / \\
1.010\end{array}$ & $\begin{array}{c}59.2 \pm 0.5 / \\
59.4 \pm 0.5\end{array}$ & $\begin{array}{c}1233 \pm 52 / \\
1276 \pm 38\end{array}$ & $\begin{array}{c}23.5 \pm 1.1 / \\
24.9 \pm 0.7\end{array}$ & $\begin{array}{l}19.1 \pm 0.7 / \\
22.5 . \pm 1.8\end{array}$ \\
\hline
\end{tabular}

It could be concluded that density, hardness, and Young's modulus increased in contrast with those for the 'UHMWPE+17\%HDPE-g-VTMS+12\%PP' composite with enhancing the CGF content. In addition, elongation at break decreased by an order of magnitude for the HC-PM composites. At the same time, it only halved for the HC-TSE ones. Additionally, the Young's modulus increased by 1.7 times over that for the non-enforced matrix in this case.

For both HC-PM and HC-TSE methods, the lowest wear rate was observed for the samples loaded with 5\% CGF (Figure 5). With enhancing the CGF contents, wear rates increased. The dynamics of the friction coefficients was similar. These results enabled us to 
conclude that the CGF loading degree over $5 \%$ was accompanied by significant counterpart wear. This, in turn, caused microabrasive wear of the composites. For this reason, wear rate increased by $30 \%$ for the composites loaded with 10\% CGF compared to that for the samples containing $5 \%$ CGF.

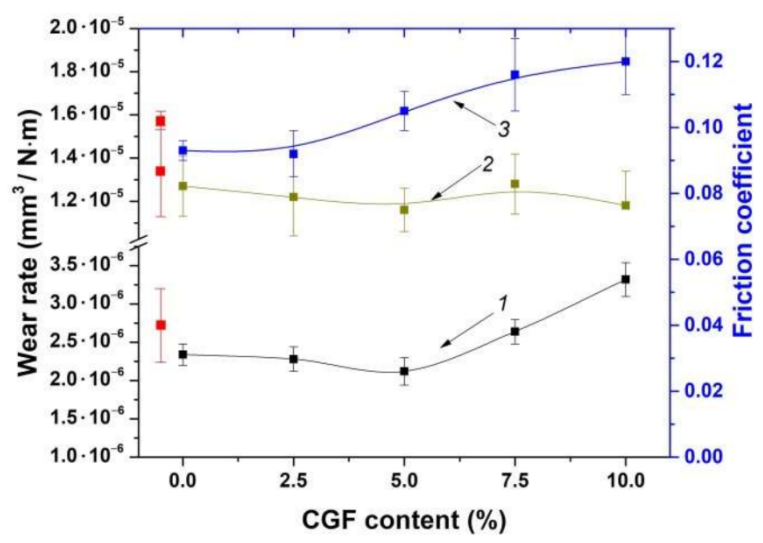

(a)

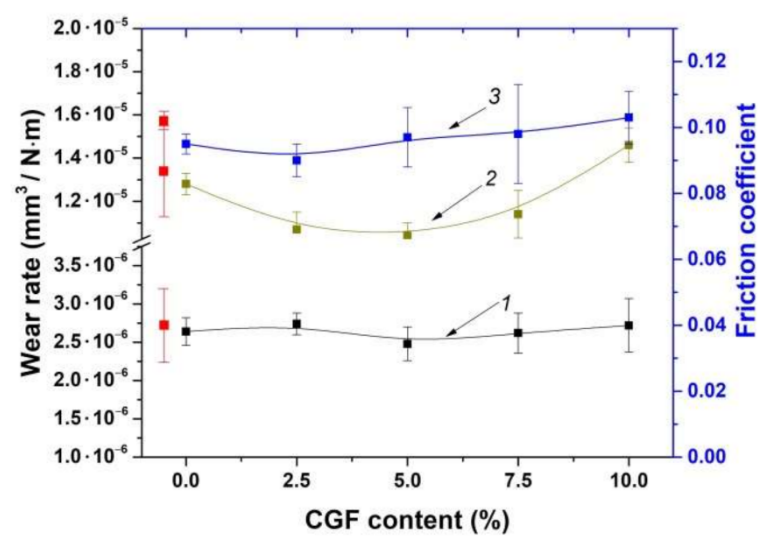

(b)

Figure 5. Wear rates according to the 'pin-on-disk' (curve 1, $5 \mathrm{~N} \cdot 0.3 \mathrm{~m} / \mathrm{s}$ ) and 'block-on-ring' (curve 2, $60 \mathrm{~N} \cdot 0.3 \mathrm{~m} / \mathrm{s}$ ) schemes as well as the average friction coefficients (curve 3) versus filler weight fraction: HC-PM (a), HC-TSE (b).

Figure 5 (curve 2) shows the wear rates of the composites under the 'mild' tribological conditions according to the 'block-on-ring' scheme. In this case, the data testified that the HC-TSE composite loaded with 5\% CGF possessed the best wear resistance.

Figure 6 presents dependencies of the Young's modulus and wear rates from the HGS, MGF, and CGF contents in the TSE composites. It follows from these data that the Young's modulus was enhanced and the wear rates also slightly rose with an increase in the HGS content. The inexpediency of loading with more than 5\% HGS could be concluded. Compared to neat UHMWPE, this improved the mechanical properties (Young's modulus by 1.6 times and yield strength by 1.2 times) while maintaining wear resistance and ensuring the sufficient extrudability level (including for additive manufacturing). With an increase in the MGF content up to 5\%, the Young's modulus increased up to $1200 \mathrm{MPa}$ with slightly enhanced wear rates. Further increase of the HGS content was not accompanied by an increase in the Young's modulus.

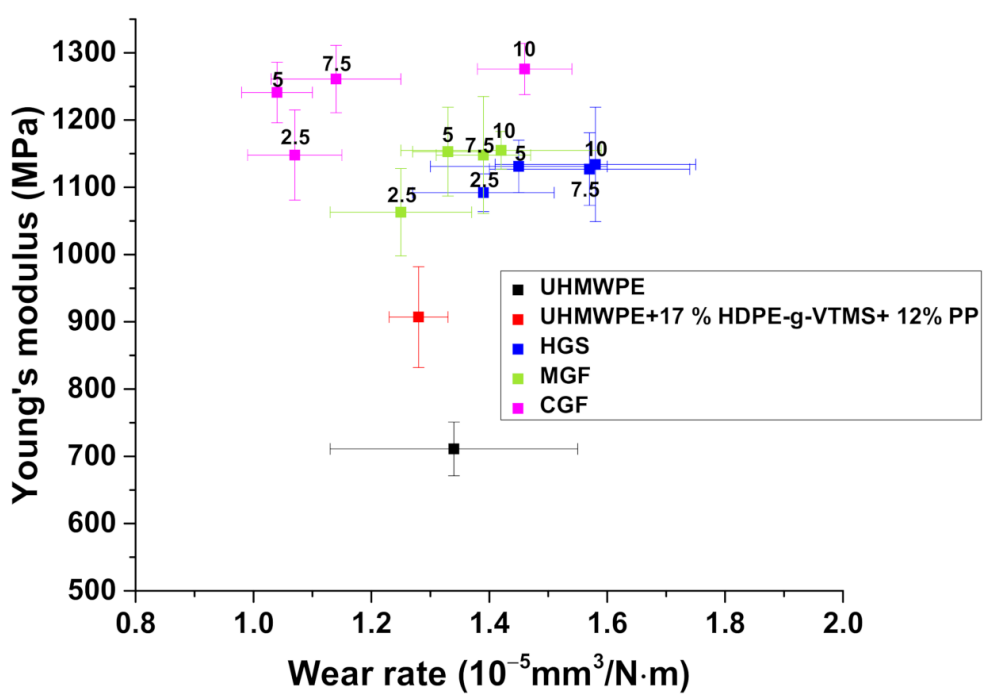

Figure 6. Young's modulus vs. wear rate (the 'block-on-ring' scheme; 60 N·0.3 m/s); HC-TSE. 
With a rise in the CGF content from 5 up to $10 \%$, the Young's modulus was enhanced by 1.7 and 1.4 times compared to neat UHMWPE and the 'UHMWPE+17\%HDPEg-VTMS $+12 \% \mathrm{PP}^{\prime}$ matrix, respectively. However, the increase in the CGF content up to $10 \%$ was also accompanied with a rise in wear rates by 1.5 times (from 1.04 up to $1.46 \cdot 10^{-5} \mathrm{~mm}^{3} / \mathrm{N} \cdot \mathrm{m}$ ) and a slight increase in Young's modulus. Based on the obtained data, the composites loaded with 5\% CGF were recommended for fabrication by the FDM-TSE method.

The results of the tribological tests of the 'UHMWPE+17\%HDPE-g-VTMS+12\%PP'based composites showed that the optimal GF content was $5 \%$ for all studied fillers (HGS, MGF, and CGF). This composition provided the improved strength properties of the multicomponent extruded matrix, high wear resistance of the composites, and the necessary MFI level to be processed by screw extrusion. Then, it was used as a feedstock for 3D-printing of the composites.

3.4. Comparative Analysis of the Composites Fabricated by the Hot Compression (HC) and Fused Deposition Modeling (FDM) Methods

A comparative analysis was carried out to investigate the structure and characteristics of the 'UHMWPE+17\%HDPE-g-VTMS+12\%PP'-based composites loaded with 5\% HGS, MGF, and CGF. Table 5 presents the mechanical properties of the composites fabricated by the HC-PM, HC-TSE, and FDM-TSE methods.

Table 5. The mechanical properties of the 'UHMWPE+17\%HDPE-g-VTMS+12\%PP'-based composites.

\begin{tabular}{|c|c|c|c|c|c|}
\hline $\begin{array}{l}\text { Filler Composition } \\
\text { (wt.\%) }\end{array}$ & Density $\rho\left(\mathrm{g} / \mathrm{cm}^{3}\right)$ & Shore D Hardness & $\begin{array}{l}\text { Young's Modulus } \\
\text { G (MPa) }\end{array}$ & $\begin{array}{c}\text { Yield Strength } \\
\sigma_{Y}(\mathrm{MPa})\end{array}$ & $\begin{array}{c}\text { Tensile Strength } \\
\sigma_{\mathrm{T}}(\mathrm{MPa})\end{array}$ \\
\hline $\begin{array}{c}\text { 0) } 17 \% \text { HDPE-g-VTMS } \\
+12 \% \text { PP (HC-PM) }\end{array}$ & 0.933 & $57.8 \pm 0.3$ & $876 \pm 71$ & $25.1 \pm 0.3$ & $19.1 \pm 1.3$ \\
\hline $\begin{array}{l}\text { 1) } 17 \% \text { HDPE-g-VTMS } \\
+12 \% \text { PP (HC-TSE) }\end{array}$ & 0.939 & $59.1 \pm 0.2$ & $907 \pm 75$ & $26.8 \pm 0.6$ & $34.3 \pm 2.7$ \\
\hline $\begin{array}{l}\text { 2) } 17 \% \text { HDPE-g-VTMS } \\
+12 \% \mathrm{PP} \text { (FDM-TSE) }\end{array}$ & 0.925 & $58.4 \pm 0.5$ & $1210 \pm 65$ & $26.4 \pm 0.6$ & $22.7 \pm 1.9$ \\
\hline$+5 \%$ HGS (HC-PM) / & $0.972 /$ & $58.1 \pm 0.5 /$ & $872 \pm 72 /$ & $23.2 \pm 0.4 /$ & $18.4 \pm 1.5 /$ \\
\hline$+5 \%$ MGF (HC-PM)/ & $0.947 /$ & $59.9 \pm 0.6 /$ & $1063 \pm 65 /$ & $24.1 \pm 1.9 /$ & $19.9 \pm 0.5 /$ \\
\hline +5\% CGF (HC-PM) & 0.984 & $58.4 \pm 0.4$ & $1208 \pm 45$ & $23.3 \pm 0.9$ & $19.2 \pm 1.5$ \\
\hline$+5 \%$ HGS (HC-TSE) / & $0.965 /$ & $58.2 \pm 0.3 /$ & $1131 \pm 39 /$ & $24.6 \pm 0.1 /$ & $27.6 \pm 0.5 /$ \\
\hline$+5 \%$ MGF (HC-TSE) $/$ & $0.945 /$ & $60.4 \pm 0.6 /$ & $1153 \pm 66 /$ & $26.5 \pm 0.9 /$ & $25.3 \pm 3.2 /$ \\
\hline +5\% CGF (HC-TSE) & 0.972 & $58.9 \pm 0.4$ & $1241 \pm 45$ & $25.2 \pm 0.4$ & $25.2 \pm 1.5$ \\
\hline$+5 \%$ HGS (FDM-TSE) $/$ & $0.937 /$ & $57.8 \pm 0.5 /$ & $1306 \pm 42 /$ & $26.9 \pm 0.3 /$ & $23.5 \pm 0.4 /$ \\
\hline$+5 \%$ MGF (FDM-TSE)/ & $0.929 /$ & $61.5 \pm 1.2 /$ & $1376 \pm 71 /$ & $29.3 \pm 0.3 /$ & $29.9 \pm 2.1 /$ \\
\hline$+5 \%$ CGF (FDM-TSE) & 0.945 & $58.5 \pm 0.7$ & $1522 \pm 58$ & $27.9 \pm 0.9$ & $24.2 \pm 0.3$ \\
\hline
\end{tabular}

The analysis of the summarized data (see Table 5) enabled us to conclude that the mechanical properties (Young's modulus and yield stress) of the FDM-TSE composites were 1.2-1.3 times higher than those for the non-enforced composite fabricated by the same method, and 10-15\% higher than those for the HC-TSE ones. This fact could be explained by the supermolecular structures of the samples (Figure 7). The supermolecular structures of the 'UHMWPE+17\%HDPE-g-VTMS+12\%PP' matrix and the HC-PM composites included spherulites, the sizes of which depended on the aspect ratio of the GF fillers. Loading the matrix with HGS resulted in a decrease in the size of spherulites from 150 down to $50 \mu \mathrm{m}$ (Figure $7 a, d, g, j)$.

The supermolecular structures of the HC-TSE composites (Figure $7 \mathrm{~b}, \mathrm{e}, \mathrm{h}, \mathrm{k}$ ) were fundamentally different from those of the HC-PM samples. It should be noted that both UHMWPE and HDPE-g-VTMS particles were large (hundreds of microns) for technological reasons. This fact did not facilitate their uniform distribution in the matrix. As a result of compounding in the twin-screw extruder, which implemented the development of shear strain processes in the liquid state and the subsequent solidification of the polymers 
with different melting points, the sizes of PP inclusions did not exceed a couple of tens of microns. Respectively, all components were uniformly distributed in the polymer composites. The glass fibers were evenly distributed in the polymer matrix. Finally, the FDM-TSE samples had even finer and more homogeneous supermolecular structures (Figure $7 \mathrm{c}, \mathrm{f}, \mathrm{i}, \mathrm{l})$, which corresponded to their higher strength properties in comparison with those for the HC-TSE ones.

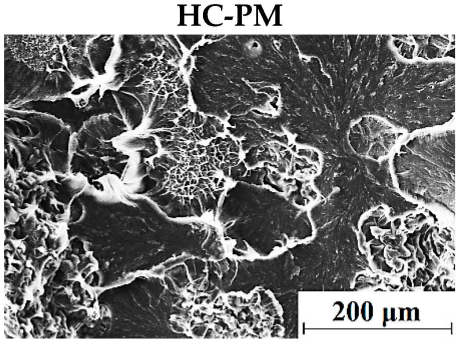

(a)

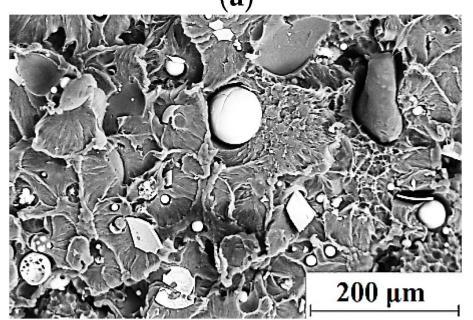

(d)

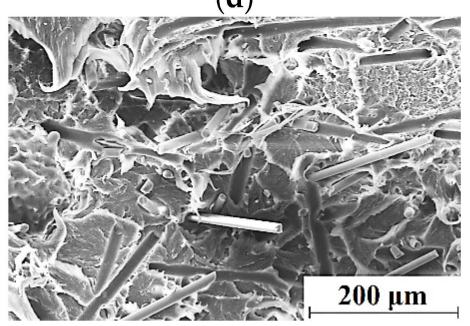

(g)

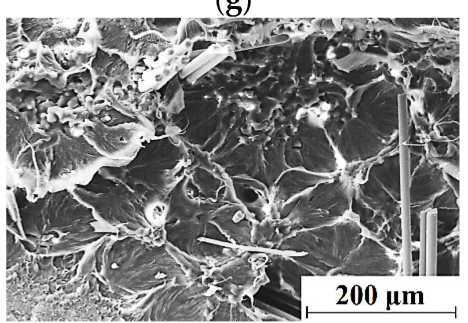

(j)

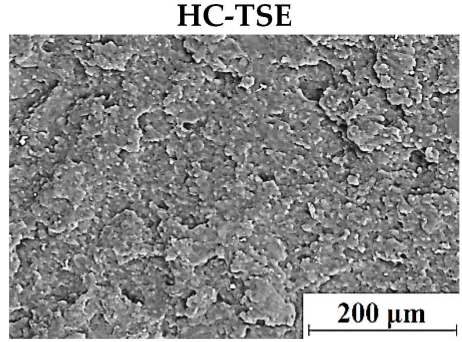

(b)

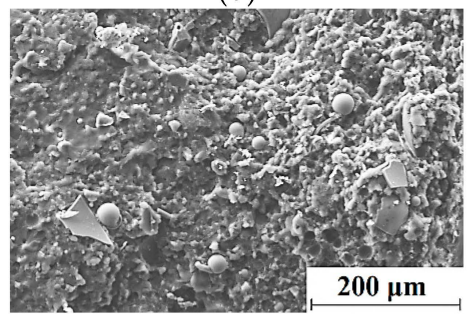

(e)

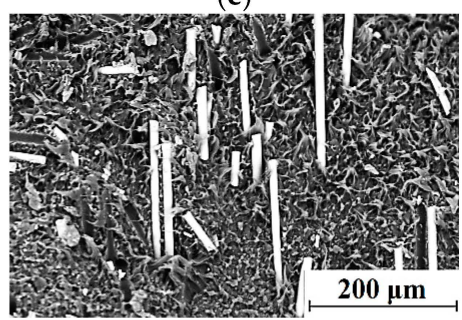

(h)

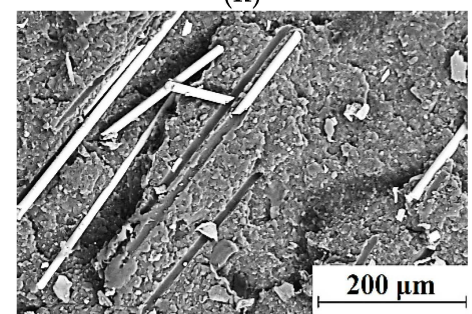

$(\mathbf{k})$

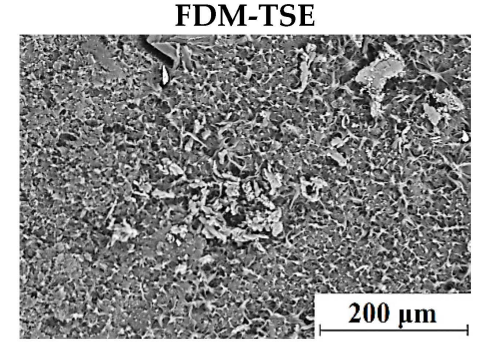

(c)

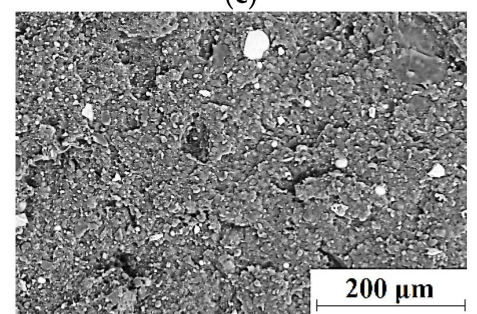

(f)

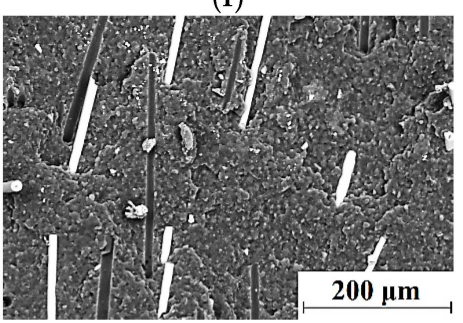

(i)

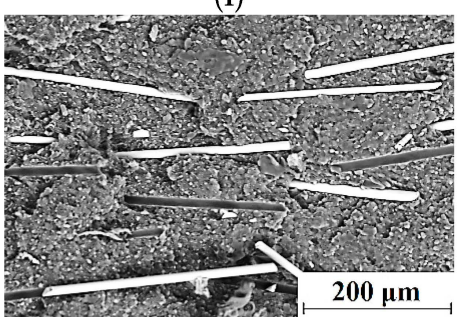

(1)

Figure 7. The SEM-micrographs of supermolecular structure of the 'UHMWPE+17\%HDPE-g-VTMS+12\%PP' sample $(\mathbf{a}-\mathbf{c})$ and the composites (d-1) fabricated by the HC-PM, HC-TSE, and FDM-TSE methods: 'UHMWPE+17\%HDPE$\mathrm{g}$-VTMS+12 \%PP+5\%HGS' (d-f); 'UHMWPE+17\%HDPE-g-VTMS+12\%PP+5\%MGF' (g-i); 'UHMWPE+17\%HDPE-gVTMS+12\%PP+5\%CGF' (j-1).

Despite the fact that the density of the composites had decreased during the FDM layer-by-layer extrusion, the mechanical properties of the FDM-TSE composites were higher than those for the HC-TSE ones. Thus, twin-screw compounding of the multi-component polymer mixtures with different sizes of the initial components made it possible to form the homogeneous supermolecular structures of the composites and, as a consequence, to provide their higher mechanical properties. The additional single-screw extrusion of granules in the FDM procedure improved (made them finer) the elements of the supermolecular structure, further enhancing the strength characteristics of the extruded matrix and the composites. In Figure $7 \mathrm{~h}, \mathrm{i}, \mathrm{k}, \mathrm{l}$, SEM micrographs indicate the presence of adhesion between the matrix and fibers in the composites. 
Table 6 presents the tribological characteristics of the 'UHMWPE+17\%HDPE-g-VTMS $+12 \% \mathrm{PP}^{\prime}$-based composites fabricated by all three methods under the dry sliding friction conditions according to the 'pin-on-disk' scheme. Their friction coefficients were significantly lower than that for neat UHMWPE, while they were weakly dependent on the sample fabrication methods. The lowest values of $\sim 0.073-0.079$ were found for the composites loaded with 5\% MGF. More clearly these dependences were drawn in Figure 8. For the 'pin-on-disk' scheme, they were consistent with wear rates, the minimum values of which were characteristic of the composites loaded with 5\% MGF (Table 6). Wear rate of the ones loaded with 5\% CGF was at the level of the 'UHMWPE+17\%HDPE-g-VTMS+12\% $\mathrm{PP}^{\prime}$ non-enforced composite.

Table 6. The tribological characteristics of neat UHMWPE and the 'UHMWPE+17\%HDPE-g-VTMS+12\%PP'-based composites. The 'pin-on-disk' scheme.

\begin{tabular}{|c|c|c|c|c|c|c|}
\hline Filler Content (\%) & \multicolumn{3}{|c|}{ Wear Rate $\left(10^{-6} \mathrm{~mm}^{3} / \mathrm{N} \cdot \mathrm{m}\right)$} & \multicolumn{3}{|c|}{ The Friction Coefficient $f$} \\
\hline \multirow[t]{2}{*}{ None } & & $2.72 \pm 0.48$ & & & $0.102 \pm 0.003$ & \\
\hline & powder & granule & 3D-printing & powder & granule & 3D-printing \\
\hline $\begin{array}{l}\text { 17\%HDPE-g- } \\
\text { VTMS+12\%PP }\end{array}$ & $2.34 \pm 0.14$ & $2.64 \pm 0.18$ & $2.28 \pm 0.23$ & $0.093 \pm 0.003$ & $0.095 \pm 0.003$ & $0.096 \pm 0.004$ \\
\hline$+5 \%$ HGS & $3.02 \pm 0.24$ & $2.54 \pm 0.32$ & $2.52 \pm 0.11$ & $0.119 \pm 0.009$ & $0.098 \pm 0.006$ & $0.099 \pm 0.003$ \\
\hline$+5 \%$ MGF & $1.96 \pm 0.06$ & $1.84 \pm 0.08$ & $2.06 \pm 0.15$ & $0.073 \pm 0.005$ & $0.075 \pm 0.004$ & $0.079 \pm 0.005$ \\
\hline$+5 \%$ CGF & $2.32 \pm 0.18$ & $2.48 \pm 0.22$ & $2.37 \pm 0.15$ & $0.105 \pm 0.006$ & $0.097 \pm 0.009$ & $0.104 \pm 0.003$ \\
\hline
\end{tabular}

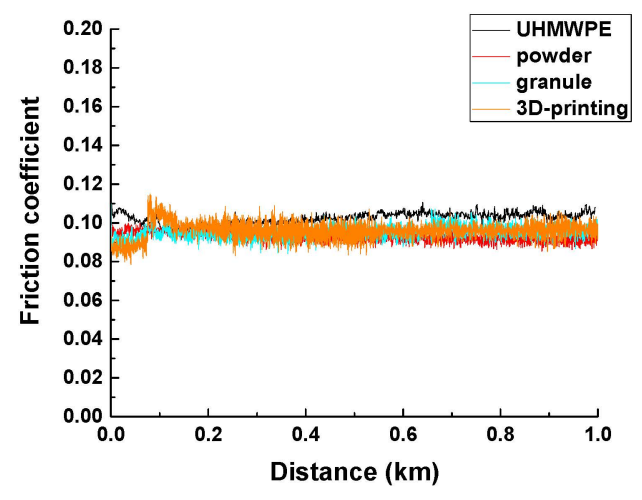

(a)

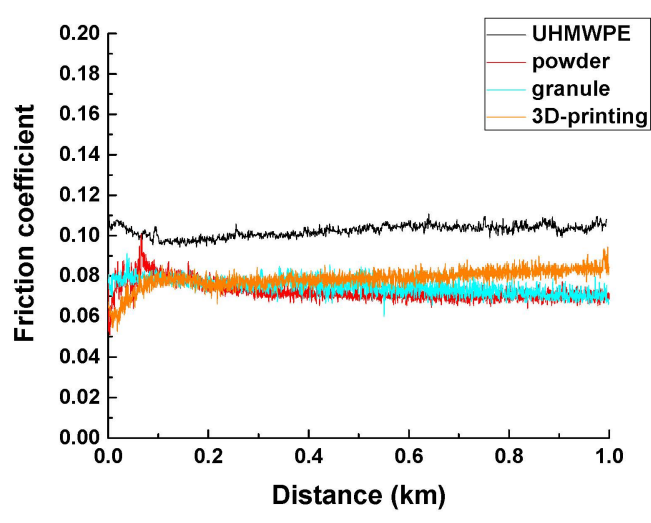

(c)

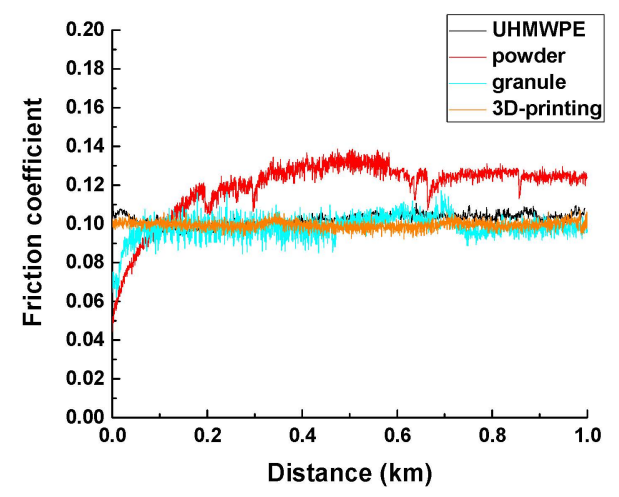

(b)

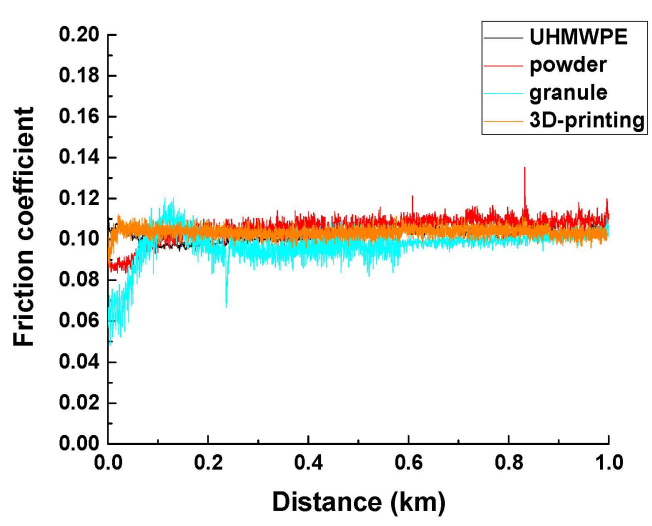

(d)

Figure 8. The friction coefficient vs the sliding distance: UHMWPE+17\%HDPE-g-VTMS+12\%PP (a), UHMWPE+17\%HDPEg-VTMS+12\%PP+5\%HGS (b), UHMWPE+17\%HDPE-g-VTMS+12\%PP+5\%MGF (c), UHMWPE+17\%HDPE-gVTMS+12\%PP+5\%CGF (d). The 'pin-on-disk' scheme. 
Figure 9 shows the optical images of the wear track surfaces of the steel counterpart after the tribological tests. Glass spheres (15-200 $\mu \mathrm{m}$ in size) and $3 \mathrm{~mm}$ chopped glass fibers, protruded above the polymer matrix, exerted a cutting effect on the counterpart surface to a greater extent in the FDM-TSE cases (Figure 9c,f,i).

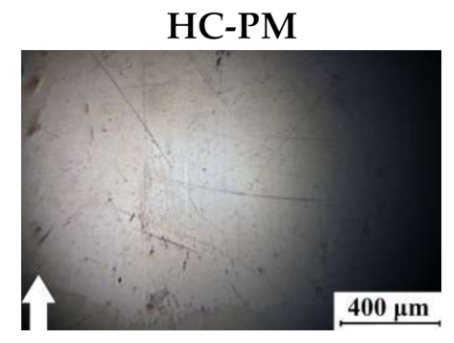

(a)

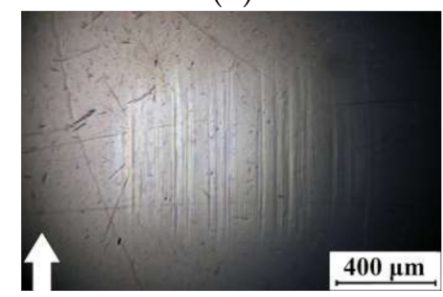

(d)

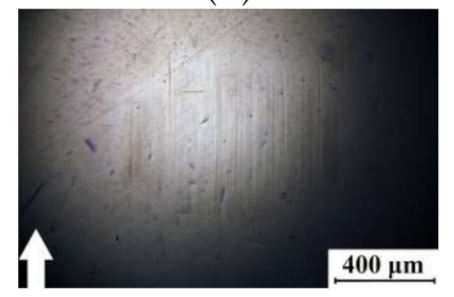

(g)

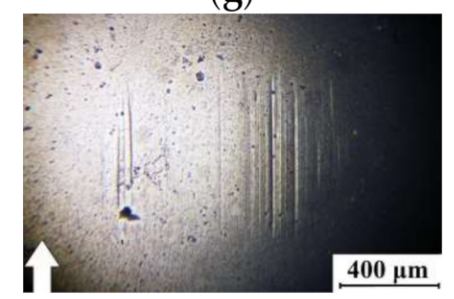

(j)

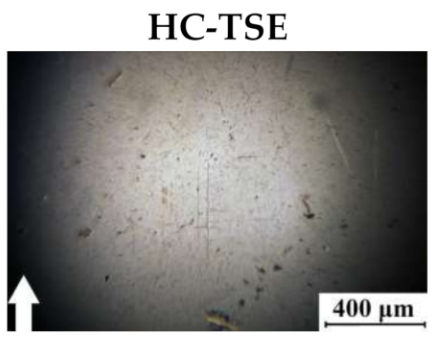

(b)

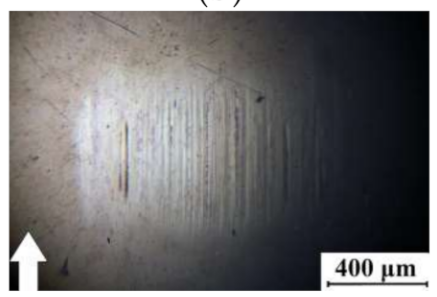

(e)

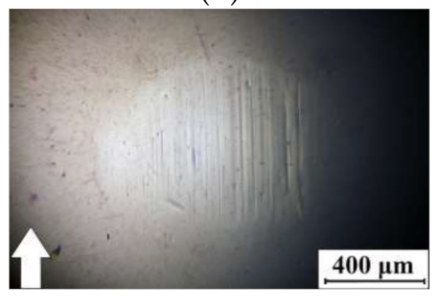

(h)

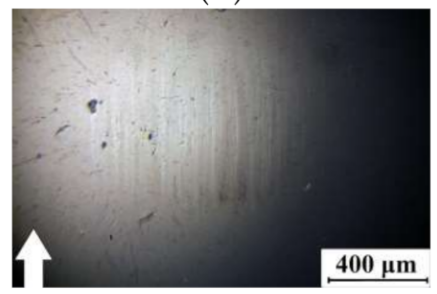

(k)

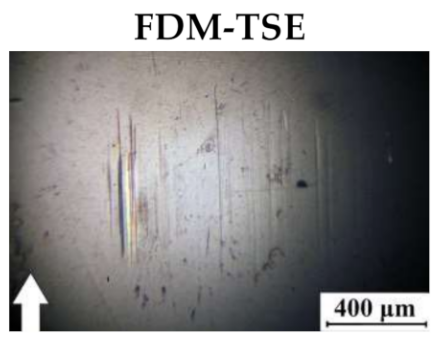

(c)

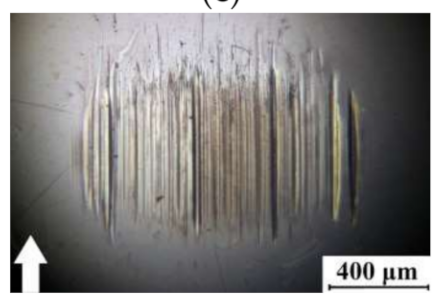

(f)

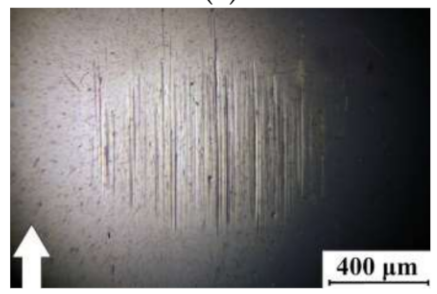

(i)

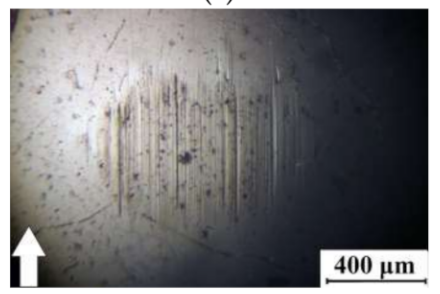

(1)

Figure 9. The wear track surfaces on the steel counterpart after the tribological tests on the 'UHMWPE+17\%HDPEg-VTMS+12\%PP' sample $(\mathbf{a}-\mathbf{c})$ and the composites (d-l) fabricated by the HC-PM, HC-TSE, and FDM-TSE methods: 'UHMWPE+17\%HDPE-g-VTMS+12\%PP+5\%HGS' (d-f); 'UHMWPE+17\%HDPE-g-VTMS+12\%PP+5\%MGF' (g-i); 'UHMWPE+17\%HDPE-g-VTMS+12\%PP+5\%CGF' (j-1). The 'pin-on-disk' scheme.

Furthermore, the tribological characteristics, the structure, and the topography of the wear track surfaces on both the counterpart and the composites were investigated under the 'mild' and 'severe' conditions according to the 'block-on-ring' scheme in order to determine the possible load-speed parameters for their operation in friction units (Table 7).

It follows from Table 8 that the composite loaded with 5\% MGF and fabricated by the FDM-TSE method was the most efficient. Under the 'mild' tribological conditions, its wear rate was $0.96 \cdot 10^{-5} \mathrm{~mm}^{3} / \mathrm{N} \cdot \mathrm{m}$. Under the 'severe' tribological conditions, the highest wear resistance was shown by the sample loaded with 5\% CGF and manufactured by the same procedure (wear rate of $1.91 \cdot 10^{-5} \mathrm{~mm}^{3} / \mathrm{N} \cdot \mathrm{m}$ ). Thus, the fabrication methods (the number of processing passes in the twin screw extruder) and the filler sizes (the aspect ratio) determined the predominant load-speed operation parameters of the 'UHMWPE+17\%HDPE-g-VTMS+12\%PP'-based composites. 
Table 7. The tribological characteristics of neat UHMWPE and the 'UHMWPE+17\%HDPE-g-VTMS+12\%PP'-based composites. The 'block-on-ring' scheme.

\begin{tabular}{|c|c|c|c|c|c|c|}
\hline \multirow{3}{*}{$\begin{array}{c}\text { Filler Content (\%) } \\
\text { None } \\
\end{array}$} & \multicolumn{3}{|c|}{$\begin{array}{l}\text { Wear Rate }\left(10^{-5} \mathrm{~mm}^{3} / \mathrm{N} \cdot \mathrm{m}\right) \\
\text { (Test Conditions-60 N.0.3 m/s) }\end{array}$} & \multicolumn{3}{|c|}{$\begin{array}{l}\text { Wear Rate }\left(10^{-5} \mathrm{~mm}^{3} / \mathrm{N} \cdot \mathrm{m}\right) \\
\text { (Test Conditions-140 N.0.5 m/s) }\end{array}$} \\
\hline & \multicolumn{3}{|c|}{$1.34 \pm 0.21$} & \multicolumn{3}{|c|}{$3.30 \pm 0.39$} \\
\hline & powder & granule & 3D-printing & powder & granule & 3D-printing \\
\hline $\begin{array}{l}\text { 17\%HDPE-g- } \\
\text { VTMS+12\%PP }\end{array}$ & $1.27 \pm 0.14$ & $1.28 \pm 0.05$ & $1.25 \pm 0.13$ & $2.25 \pm 0.09$ & $2.10 \pm 0.08$ & $2.19 \pm 0.20$ \\
\hline$+5 \%$ HGS & $1.34 \pm 0.15$ & $1.45 \pm 0.15$ & $1.11 \pm 0.07$ & $2.28 \pm 0.29$ & $1.96 \pm 0.17$ & $2.09 \pm 0.06$ \\
\hline$+5 \%$ MGF & $1.40 \pm 0.15$ & $1.33 \pm 0.06$ & $0.96 \pm 0.15$ & $2.70 \pm 0.17$ & $2.49 \pm 0.34$ & $2.12 \pm 0.14$ \\
\hline$+5 \%$ CGF & $1.16 \pm 0.10$ & $1.04 \pm 0.06$ & $1.38 \pm 0.08$ & $2.31 \pm 0.41$ & $2.23 \pm 0.05$ & $1.91 \pm 0.14$ \\
\hline
\end{tabular}

Table 8. The counterpart temperatures upon friction on neat UHMWPE and the 'UHMWPE+17\%HDPE-g-VTMS+12\%PP'based composites under various tribological conditions. The 'block-on-ring' scheme.

\begin{tabular}{|c|c|c|c|c|c|c|}
\hline \multirow{3}{*}{$\begin{array}{c}\text { Filler Content, \% } \\
\text { None }\end{array}$} & \multicolumn{3}{|c|}{$\begin{array}{c}\text { Temperature }\left({ }^{\circ} \mathrm{C}\right) \\
\text { (Test Conditions-60 N.0.3 m/s) }\end{array}$} & \multicolumn{3}{|c|}{$\begin{array}{c}\text { Temperature }\left({ }^{\circ} \mathrm{C}\right) \\
\text { (Test Conditions-140 N.0.5 m/s) }\end{array}$} \\
\hline & \multicolumn{3}{|c|}{$31.4 \pm 2$} & \multicolumn{3}{|c|}{$58.4 \pm 2$} \\
\hline & powder & granules & 3D-printing & powder & granules & 3D-printing \\
\hline $\begin{array}{l}\text { 17\%HDPE-g- } \\
\text { VTMS+12\%PP }\end{array}$ & $28.8 \pm 2$ & $29.4 \pm 2$ & $31.5 \pm 2$ & $49.5 \pm 2$ & $49.6 \pm 2$ & $52.5 \pm 2$ \\
\hline$+5 \%$ HGS & $26.4 \pm 2$ & $26.8 \pm 2$ & $31.0 \pm 2$ & $53.4 \pm 2$ & $50.5 \pm 2$ & $52.6 \pm 2$ \\
\hline$+5 \% \mathrm{MGF}$ & $26.1 \pm 2$ & $26.6 \pm 2$ & $29.6 \pm 2$ & $52.1 \pm 2$ & $44.1 \pm 2$ & $43.2 \pm 2$ \\
\hline$+5 \%$ CGF & $28.8 \pm 2$ & $27.4 \pm 2$ & $31.7 \pm 2$ & $48.1 \pm 2$ & $50.8 \pm 2$ & $51.7 \pm 2$ \\
\hline
\end{tabular}

Figures 10 and 11 show the micrographs of the wear track surfaces on the 'UHMWPE $+17 \%$ HDPE-g-VTMS+12\%PP'-based composites fabricated by the HC-PM, HC-TSE, and FDM-TSE methods. Under the 'mild' tribological conditions, the smoothest surface of the matrix samples was typical for the FDM-TSE case (Figure 10c). On the wear track surface of the most wear-resistant FDM-TSE composite (Figure 10i), the grooves were formed, highly likely, due to its low density (e.g., compared to the HC-TSE one, Figure 10h). In general, the topography of the wear track surfaces of all composites could be considered similar, with the exception of the FDM-TSE sample loaded with CGF. In this case, some grooves were observed on the wear track surface. According to the authors, this was due to fiber fracture and their subsequent plowing action (Figure 101).

Under the 'severe' tribological conditions, wear rates of the composites varied less (the values were in the range of (1.91-2.70) $\left.10^{-5} \mathrm{~mm}^{3} / \mathrm{N} \cdot \mathrm{m}\right)$. For this reason, the topography of the wear track surfaces also differed to a lesser extent. In this case, the smoothest ones were characteristic of the samples fabricated by the FDM-TSE method (Figure 11c,f,i,l).

Comparison of the topography of the wear track surfaces on the 'UHMWPE+17\%HDPE$\mathrm{g}$-VTMS+12\%PP'-based composites fabricated by the HC-PM, HC-TSE, and FDM-TSE methods showed that the relief features correlated well with the tribological characteristics under both 'mild' and 'severe' tribological conditions. The observed warts on the wear track surfaces of the HC-PM samples were due to the heterogeneity of their supermolecular structure.

The wear track surfaces were smoother on the HC-TSE samples, while there was little debris adhered on the counterpart (Figures 9 and 10). The FDM-TSE samples were much more flattish; however, there was quite a lot of debris on the deep-plowed counterpart surface after friction on the composite loaded with 5\% CGF (Figure 9).

Thus, the dimensions of glass filler (the aspect ratio) and the fabrication methods of the UHMWPE-based composites (the amount of processing passes of the initial components in the extruder) determined the distribution of the fillers in the matrix and the supermolecular structure. As a consequence, their mechanical and tribological properties also varied. 
These two control parameters were used for the computer-aided design of composites with specified properties using an algorithm developed by the authors [22] to determine the acceptable load-speed ranges of their operation in friction units.

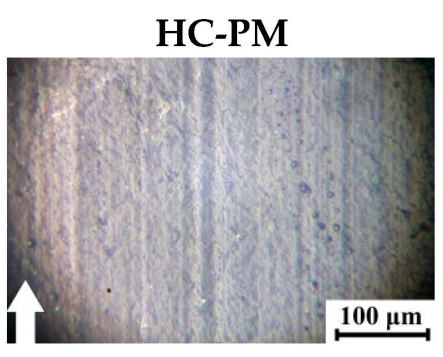

(a)

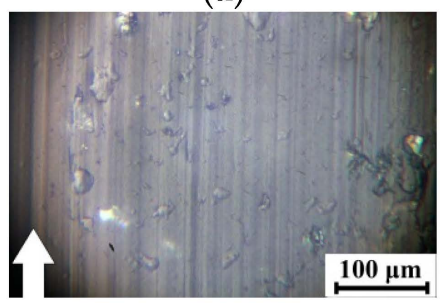

(d)

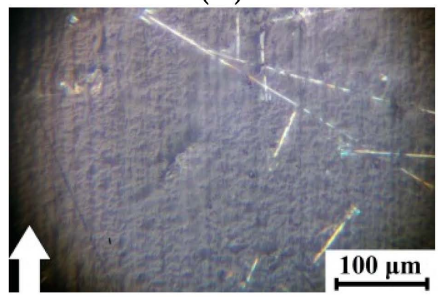

(g)

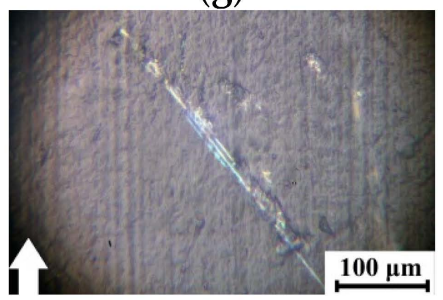

(j)

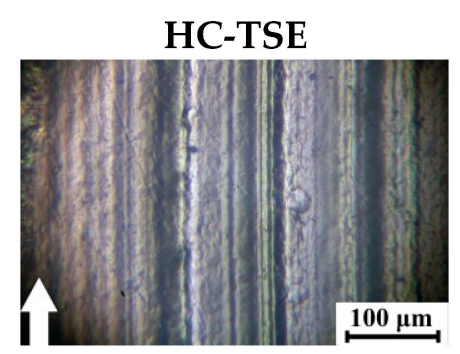

(b)

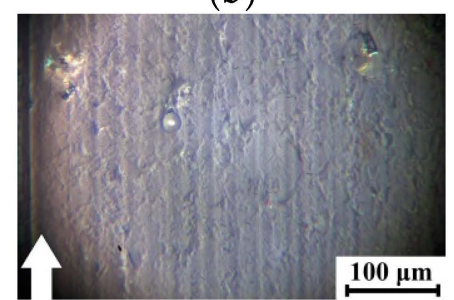

(e)

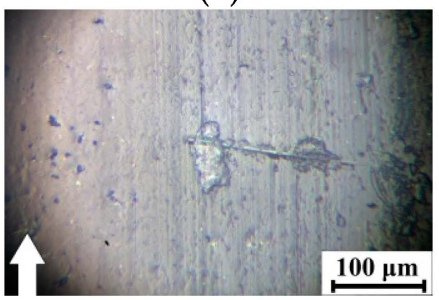

(h)

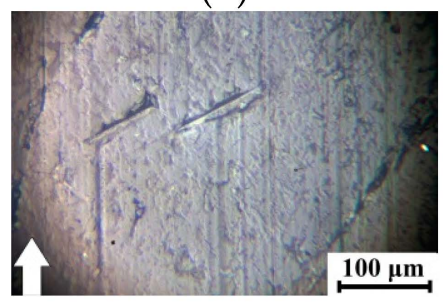

(k)

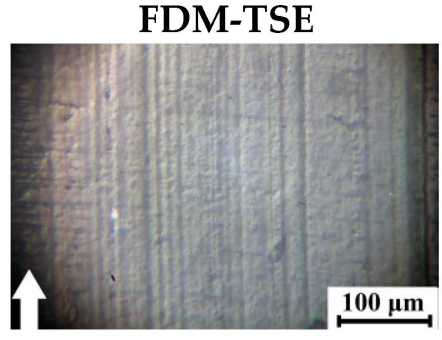

(c)

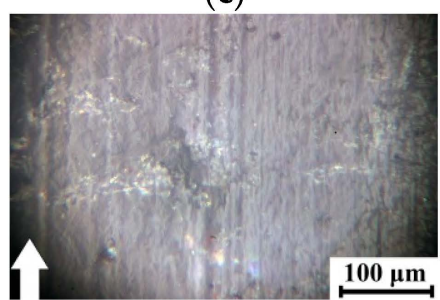

(f)

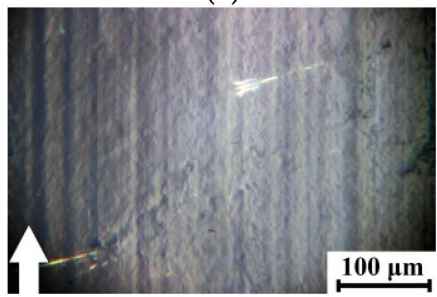

(i)

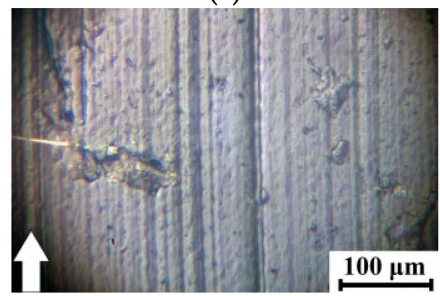

(1)

Figure 10. The wear track surfaces on the 'UHMWPE+17\%HDPE-g-VTMS+12\%PP' sample (a-c) and the composites (d-1) fabricated by the HC-PM, HC-TSE, and FDM-TSE methods: 'UHMWPE+17\%HDPE-g-VTMS+12\%PP+5\%HGS' (d-f); 'UHMWPE+17\%HDPE-g-VTMS+12\%PP+5\%MGF' (g-i); 'UHMWPE+17\%HDPE-g-VTMS+12\%PP+5\%CGF' (j-1). 60 N·0.3 m/s. 


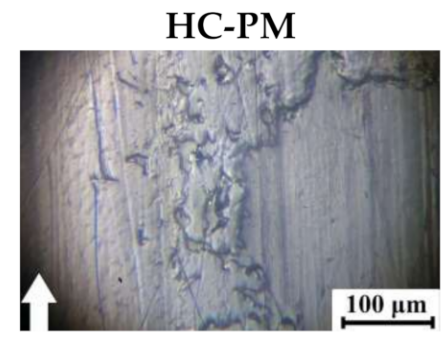

(a)

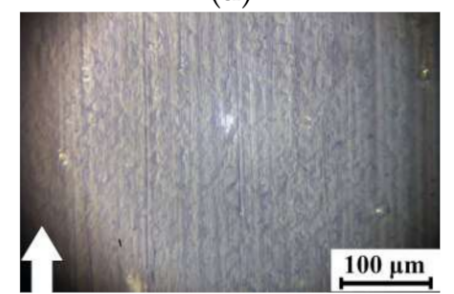

(d)

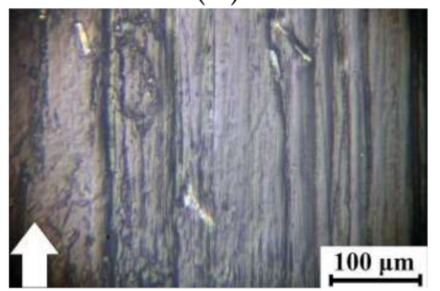

(g)

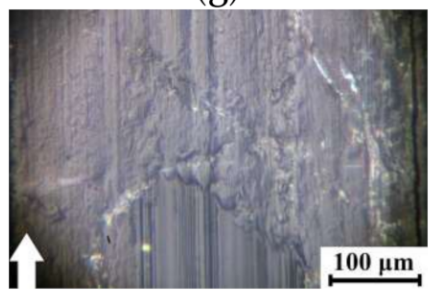

(j)

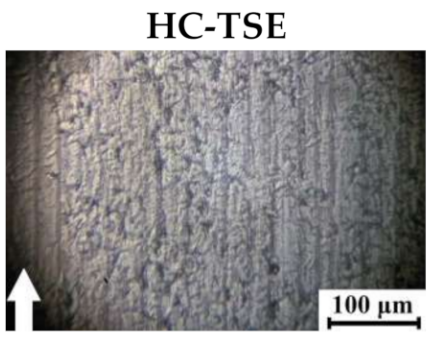

(b)

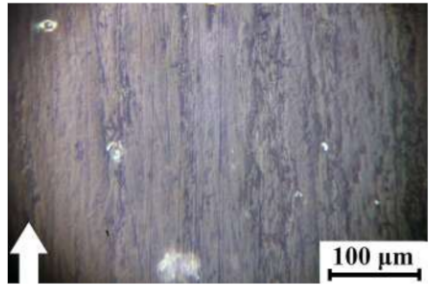

(e)

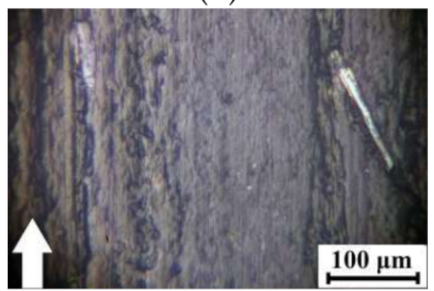

(h)

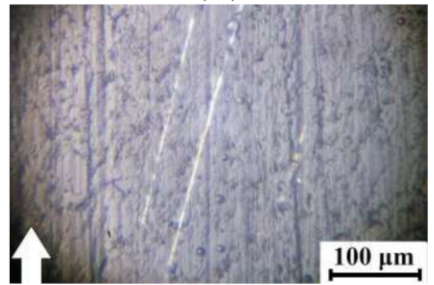

(k)
FDM-TSE

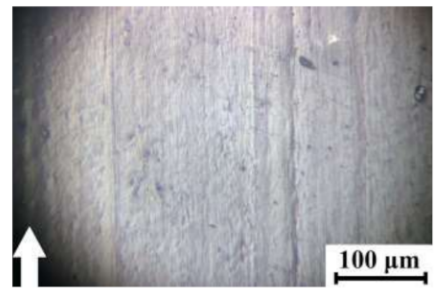

(c)

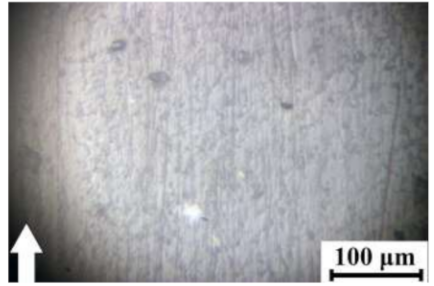

(f)

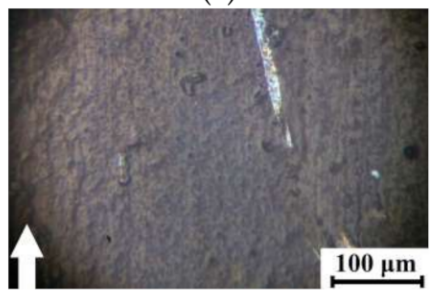

(i)

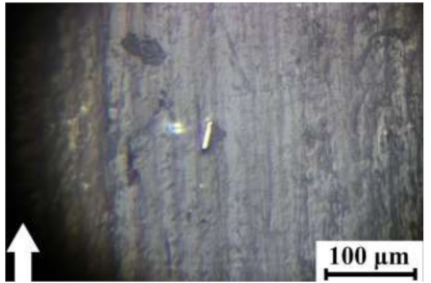

(1)

Figure 11. The wear track surfaces on the 'UHMWPE+17\%HDPE-g-VTMS+12\%PP' sample (a-c) and the composites (d-1) fabricated by the HC-PM, HC-TSE, and FDM-TSE methods: 'UHMWPE+17\%HDPE-g-VTMS+12\%PP+5\%HGS' (d-f); 'UHMWPE+17\%HDPE-g-VTMS+12\%PP+5\%MGF' (g-i); 'UHMWPE+17\%HDPE-g-VTMS+12\%PP+5\%CGF' (j-1). 140 N-0.5 m/s.

\section{Justification of Requirements for Reinforced Ultra-High-Molecular-Weight Polyethylene (UHMWPE)-Based Composites}

Using the best obtained composite, the authors proposed fabricating guides for sliding friction units. Below is a brief overview of the quantitative parameters that various manufacturers have designated as basic data for these purposes. Most companies offer a wide variety of the guide designs: for roller and plate chains, bottle guides, V-belts, conveyors, etc.

In a catalog of Misumi Group Inc. (Tokyo, Japan), the following products were offered: UHMW guide rails, UHMW guide rail shields, engineering plastic ultra-high molecular weight polyethylene irregular shaped rail, UHMW tape, wear strip (flat rail), etc. The properties of the materials for their manufacturing are presented in Table 9.

Guangzhou Engineering Plastics (Guangdong, China (Mainland)) have also developed products for similar purposes, namely: Engineering Plastics UHMWPE plastic bend guide, UHMWPE guide rail UHMWPE linear guide, UHMWPE sliding conveyor chain guide, and extruding guide plastic UHMWPE linear straight guide rail. The properties of the materials for their manufacturing are presented in Table 10. 
Table 9. The properties of the materials fabricated by the 'Misumi Group Inc.' [42].

\begin{tabular}{cc}
\hline Properties & Values \\
\hline Density $\left(\mathrm{g} / \mathrm{cm}^{3}\right)$ & 0.94 \\
Ultimate tensile strength $(\mathrm{MPa})$ & 44 \\
Elongation at break $(\%)$ & 450 \\
Rockwell R Hardness & 40 \\
Izod impact strength $(\mathrm{kJ} / \mathrm{m})$ & $>137$ \\
The friction coefficient under dry friction conditions & $0.07-0.22$ \\
The friction coefficient under lubrication conditions & $0.05-0.10$ \\
\hline
\end{tabular}

Table 10. The properties of the materials fabricated by 'Guangzhou Engineering Plastics' [43].

\begin{tabular}{cc}
\hline Properties & Values \\
\hline Density $\left(\mathrm{g} / \mathrm{cm}^{3}\right)$ & $0.94-0.96$ \\
Ultimate tensile strength $(\mathrm{MPa})\left(23^{\circ} \mathrm{C}\right)$ & 22 \\
Breaking strength $(\mathrm{MPa})$ & 42 \\
Elongation at break $(\%)$ & 600 \\
Charpy impact strength (unnotched) $\left(\mathrm{kJ} / \mathrm{m}^{2}\right)$ & Without fracture \\
Shore D hardness & 65 \\
Abrasion resistance (Sand Slurry Test) & 100 \\
The friction coefficient & $0.09-0.10$ \\
\hline
\end{tabular}

In the catalog of Polymer Industries (Henagar, AL, USA), the Polyslick UHMW products were offered in addition to the guides: bus curb, fender pads, flexi fend, pile guards, rocket plate, UHMW rod, UHMW sheet, etc. The properties of the materials for their manufacturing are presented in Table 11.

Table 11. The properties of the materials fabricated by 'Polymer Industries' [44].

\begin{tabular}{ccc}
\hline Properties & Test Method & Values \\
\hline Density $\left(\mathrm{g} / \mathrm{cm}^{3}\right)$ & {$[45]$} & 0.932 \\
Ultimate tensile strength $(\mathrm{MPa})$ & {$[46]$} & 24 \\
Tensile Young's modulus $(\mathrm{MPa})$ & {$[46]$} & $770(112,000)$ \\
Elongation at break $(\%)$ & {$[46]$} & 300 \\
The friction coefficient (static) & {$[47]$} & 0.2 \\
The friction coefficient (dynamic) & {$[47]$} & 0.15 \\
Abrasion resistance & - & 10 \\
Izod impact strength $(\mathrm{kJ} / \mathrm{m})$ & {$[48]$} & $>100$ \\
Shore D hardness & {$[49]$} & 64 \\
\hline
\end{tabular}

Tangyin Dingyuan Engineering Plastics Co. Ltd. (Anyang, Henan, China) manufactured the following products: UHMW sheet, belt conveyor roller, wear resistant light and strong UHMWPE scraper, customized UHMW parts including UHMW scraper, UHMW bearing, UHMW gears, UHMW washers, and plastic chain guide rails. The properties of the materials for their manufacturing are presented in Table 12.

The Polystone ${ }^{\circledR}$ M natural (PE-UHMW / PE 1000) material was produced by Röchling Engineering Plastics (Mannheim, Baden-Württemberg, Germany), which was also used as the base for the guides (Table 13).

The TIVAR ${ }^{\circledR} 1000$ (neat UHMWPE) and TIVAR ${ }^{\circledR} 88$ (glass-filled) materials, analogous to Polystone ${ }^{\circledR}$ M UHMWPE were manufactured by Quadrant Engineering Plastics Products, a part of the Mitsubishi Chemical Advanced Materials group (Lenzburg, Switzerland). Their properties are presented in Tables 14 and 15, respectively. 
Table 12. The properties of the materials fabricated by 'Tangyin Dingyuan Engineering Plastics Co. Ltd.' [50].

\begin{tabular}{cc}
\hline Properties & Values \\
\hline Density $\left(\mathrm{g} / \mathrm{cm}^{3}\right)$ & $0.93-0.96$ \\
Average molecular weight $\left(10^{6} \mathrm{~g} / \mathrm{mol}\right)$ & $3-10$ \\
Yield strength $(\mathrm{MPa})\left(23^{\circ} \mathrm{C}\right.$ in air) & 22 \\
Ultimate tensile strength $(\mathrm{MPa})$ & 42 \\
Charpy impact strength (notched) $\left(\mathrm{mJ} / \mathrm{mm}^{2}\right)$ & Without fracture \\
Ball indentation hardness $(\mathrm{MPa})$ & 42 \\
Shore D hardness & $65-70$ \\
Abrasion resistance & $70-80(100$ on steel $)$ \\
The friction coefficient $($ static $)$ & $\leq 0.16$ \\
The friction coefficient $($ dynamic $)$ & $\leq 0.10$ \\
Water absorption $(\%)$ & 0 \\
Elongation at break $(\%)\left(23^{\circ} \mathrm{C}\right)$ & $\geq 300$ \\
\hline
\end{tabular}

Table 13. The properties of the 'Polystone ${ }^{\circledR} \mathrm{M}$ natural' material fabricated by 'Röchling Engineering Plastics' [51].

\begin{tabular}{ccc}
\hline Properties & Test Method & Values \\
\hline Density $\left(\mathrm{g} / \mathrm{cm}^{3}\right)$ & {$[52]$} & 0.93 \\
Water absorption $(\%)$ & {$[53]$} & $<0.01$ \\
Molecular weight $\left(10^{6} \mathrm{~g} / \mathrm{mol}\right)$ & - & $\sim 9$ \\
Yield strength $(\mathrm{MPa})$ & {$[54]$} & 20 \\
Elongation at break $(\%)$ & {$[54]$} & $>200$ \\
Tensile Young's modulus $(\mathrm{MPa})$ & {$[54]$} & 680 \\
Impact strength $\left(\mathrm{kJ} / \mathrm{m}^{2}\right)$ & {$[55]$} & Without fracture \\
Shore D hardness & {$[56]$} & 63 \\
\hline
\end{tabular}

Table 14. The properties of the 'TIVAR ${ }^{\circledR} 1000^{\prime}$ material fabricated by 'Mitsubishi Chemical Advanced Materials' [57].

\begin{tabular}{ccc}
\hline Properties & Test Method & Values \\
\hline Density $\left(\mathrm{g} / \mathrm{cm}^{3}\right)$ & {$[52]$} & 0.93 \\
Average molecular weight $\left(10^{6} \mathrm{~g} / \mathrm{mol}\right)$ & - & 5 \\
Water absorption $(\%)$ & {$[53]$} & $<0.1$ \\
Ultimate tensile strength $(\mathrm{MPa})$ & {$[54]$} & 19 \\
Elongation at yield point $(\%)$ & {$[54]$} & 15 \\
Elongation at break $(\%)$ & {$[54]$} & $>50$ \\
Tensile Young's modulus $(\mathrm{MPa})$ & {$[54]$} & 750 \\
Shore D hardness & {$[56]$} & 60 \\
Charpy impact strength (unnotched) $\left(\mathrm{kJ} / \mathrm{m}^{2}\right)$ & {$[55]$} & Without fracture \\
Charpy impact strength (notched) $\left(\mathrm{kJ} / \mathrm{m}^{2}\right)$ & {$[55]$} & 115 \\
The friction coefficient $(\mathrm{dynamic})$ & {$[58]$} & $0.15-0.30$ \\
Wear rate $(\mu \mathrm{m} / \mathrm{km})$ & {$[58]$} & 8 \\
\hline
\end{tabular}

Table 15. The properties of the 'TIVAR ${ }^{\circledR} 88^{\prime}$ material fabricated by 'Mitsubishi Chemical Advanced Materials'.

\begin{tabular}{ccc}
\hline Properties & Test Method & Values \\
\hline Density $\left(\mathrm{g} / \mathrm{cm}^{3}\right)$ & {$[52]$} & 0.93 \\
Ultimate tensile strength $(\mathrm{MPa})$ & {$[46]$} & 40 \\
Tensile Young's modulus $(\mathrm{MPa})$ & {$[46]$} & $420(61,000)$ \\
Elongation at break $(\%)$ & {$[46]$} & 300 \\
Shore D hardness & {$[49]$} & 69 \\
Izod impact strength (unnotched) $(\mathrm{kJ} / \mathrm{m})$ & {$[59]$} & Without fracture \\
\hline
\end{tabular}


Murtfeldt Kunststoffe GmbH KG (Dortmund, Germany), one of the world's leading manufacturers of slide profiles, fabricated chain guides and belts, tensioning devices, and various mechanical sliding components made of wear-resistant polymers. The properties of its Werkstoff' $\mathrm{S}^{\prime}{ }^{\circledR}\left(\mathrm{PE} 1000^{\prime} \mathrm{S}^{\prime}\right)$ material are presented in Table 16.

Table 16. The properties of the 'Werkstoff' $\mathrm{S}^{\circledR} \mathrm{PE} 1000$ ' $\mathrm{S}^{\prime \prime}$ material fabricated by 'Murtfeldt Kunststoffe $\mathrm{GmbH} \& \mathrm{Co}$. KG' [60].

\begin{tabular}{ccc}
\hline Properties & Test Method & Values \\
\hline Average molecular weight $\left(10^{6} \mathrm{~g} / \mathrm{mol}\right)$ & - & $\sim 5$ \\
Density $\left(\mathrm{g} / \mathrm{cm}^{3}\right)$ & {$[52]$} & 0.93 \\
Water absorption $(\%)$ & {$[53]$} & $<0.01$ \\
Yield strength / Ultimate tensile strength, $\mathrm{MPa}$ & {$[54]$} & $\geq 17 /-$ \\
Elongation at break $(\%)$ & {$[54]$} & 700 \\
Tensile Young's modulus $(\mathrm{MPa})$ & {$[54]$} & Without fracture \\
Charpy impact strength (unnotched) $\left(\mathrm{kJ} / \mathrm{m}^{2}\right)$ & {$[55]$} & $\geq 170$ \\
Charpy impact strength (notched) $\left(\mathrm{kJ} / \mathrm{m}^{2}\right)$ & {$[55]$} & 38 \\
Ball indentation hardness $(\mathrm{MPa})$ & {$[61]$} & 66 \\
Shore D hardness & {$[56]$} & $0.1-0.2$ \\
\hline
\end{tabular}

Based on the above data, the authors applied the following physical, mechanical, and tribological properties of the materials as threshold values:

Bulleted lists look like this (reference data for neat UHMWPE were taken from the authors' data):

- Tensile Young's modulus of $1200 \mathrm{MPa}$. This level exceeded by 400-500 MPa those for all studied neat UHMWPE specimens;

- Yield strength of $25 \mathrm{MPa}$. In this case, the authors used the threshold value above that for neat UHMWPE;

- Ultimate tensile strength of $24 \mathrm{MPa}$. This level was taken slightly lower than that for neat UHMWPE, since polymer reinforcement was accompanied by the significant decrease in elongation at break, and, accordingly, in ultimate tensile strength. However, this value was high enough even for neat UHMWPE;

- Elongation at break of 200\%. This threshold was chosen based on the above data (Tables 1-8), where the minimum values ranged from 200 up to $300 \%$. In this case, the authors proceeded from the assumption that an increase in the strength properties due to the GF reinforcement should not be accompanied by a decrease in elongation at break by more than two times in regard to that for neat UHMWPE $(\sim 485 \%)$;

- The friction coefficient of 0.102. According to the published data, the friction coefficients were weakly correlated with wear resistance. In this case, the value was chosen at the neat UHMWPE level of about 0.1 (Tables 1-8);

- Wear rate of $1.1 \cdot 10^{-5} \mathrm{~mm}^{3} / \mathrm{N} \cdot \mathrm{m}$ under the 'mild' tribological conditions. The threshold value was predefined to provide $20 \%$ higher wear resistance relative to that for neat UHMWPE;

- Wear rate of $2.2 \cdot 10^{-5} \cdot \mathrm{mm}^{3} / \mathrm{N} \cdot \mathrm{m}$ under the 'severe' tribological conditions, at which the multiple higher wear rates were observed in comparison with the previous case and should be considered as short-acting ones.

\section{The Composite Design Algorithm for the Guides}

Considering the results described in Section 3, the optimal values of the control parameters were further determined, namely (i) the number of processing passes in the extruder and (ii) the aspect ratio of the glass filler. The aim was to provide the required mechanical and tribological properties of the composites, substantiated in Section 4 . For this purpose, an approach to their rational design was implemented $[62,63]$, based on the use of a limited amount of the experimental data (Tables 5-7), which were supplemented 
by applying an interpolation procedure in order to obtain continuous dependences. Then, these dependencies on the composite fabrication parameters (in this case, (i) the number of processing passes in the extruder and (ii) the aspect ratio of the glass filler) were drawn in the form of isolines, on which an area with the specified restrictions was assessed. The resulting graphs of all characteristics were superimposed on each other, which limited the area met the specified requirements. The visualization of the calculated data simplified the assessment of the influence of the control parameters on the properties of the composites and made it possible to determine their specific values required for manufacturing the materials with the predefined properties.

In the studied case, the experimentally obtained properties of the composites (Tables 5-7) were determined by the control parameters: the number of processing passes in the extruder ( 0 for HC-PM; 1 for HC-TSE; and 2 for FDM-TSE) as well as the aspect ratio of the glass filler ( 1 for HGS; 20 for MGF; and 300 for CGF). The values of other parameters were constant (the loading degree of $5 \%$, fiberglass diameters, etc.). Additional values were assessed by the interpolation [64] for intermediate points between the above-mentioned aspect ratios of the glass fillers. Distances between the nodes determining such aspect ratios were incommensurable. This resulted in large interpolation errors, even despite the use of a polynomial for unequally spaced nodes [64]. In order to change the distances between the nodes and reduce the interpolation errors, the values of the interpolation nodes were logarithmized using the natural $\operatorname{logarithm}(\ln (1)=0 ; \ln (20)=3, \ln (300)=5.7)$. The obtained data were used as the node points.

When drawing the isolines for all composite properties (Figure 12), the number of processing passes in the extruder and the aspect ratio of the glass filler were plotted along the $\mathrm{X}$ - and $\mathrm{Y}$-axis, respectively. All node values were normalized from 0 to 1 to align the plots if different node points were used for various properties. The area that met the required limits was highlighted in color for each parameter.

The overlaid areas of intersections of all graphs and isolines are shown in Figure 13. They determined the preferred number of processing passes in the extruder and the aspect ratio for the fabrication of the composites with the predefined properties. Recall that the processing passes in the extruder were not the number of sequential compounding, but the procedures associated with mixing in (i) the twin-screw extruder and (ii) FDM printing in the printer equipped with the micro-extruder.

According to Figure 13, the only composite loaded with MGF and fabricated by the FDM-TSE method was in the highlighted 'green' area.

This result was explained precisely by the possibility of uniform distribution of glass fibers in the polymer matrix, which enabled the achievement of high mechanical and tribological properties under the conditions of chemical adhesion (the presence of grafted VTMS groups). Loading UHMWPE with HGS (15-200 $\mu \mathrm{m}$ in size) did not allow being in the range of the specified parameters mainly due to the high wear rates (Figure 12m,n). On the other hand, CGF $3 \mathrm{~mm}$ in length protruded above the polymer matrix surfaces and had a scratching effect on the counterpart surface, which also caused the increase in wear rates. This excluded their use as the guides for friction units. 


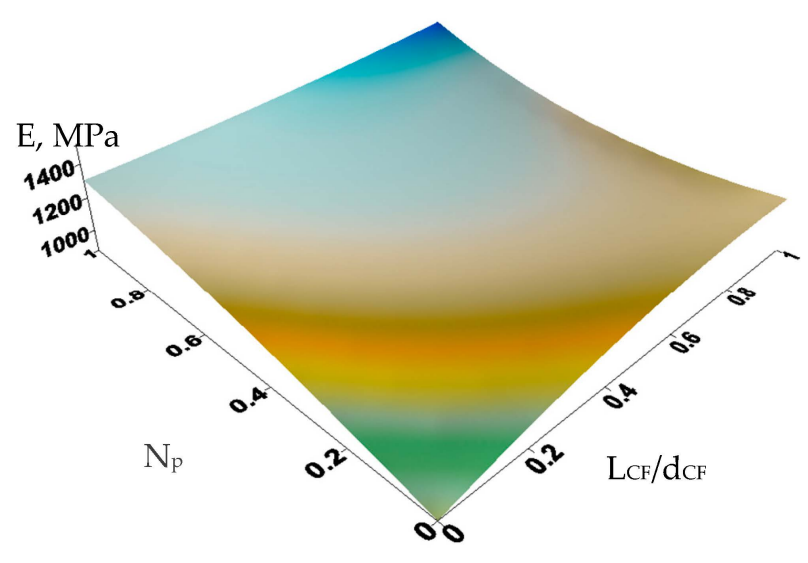

(a)

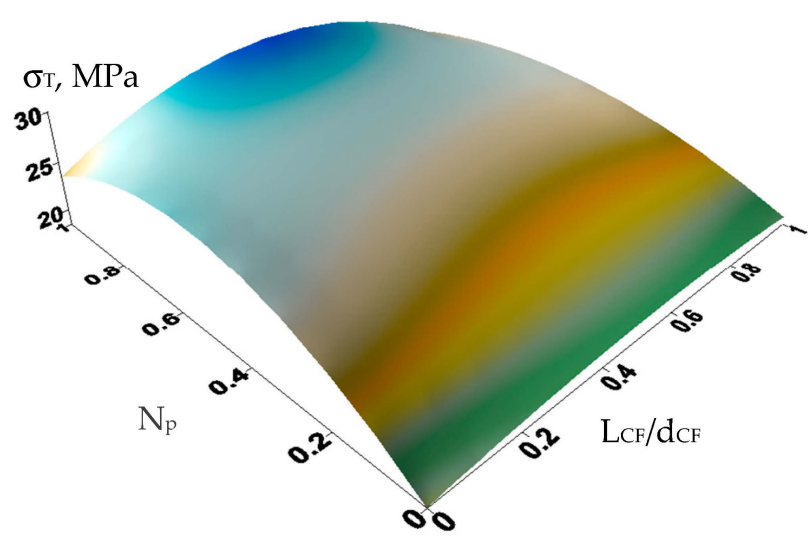

(c)

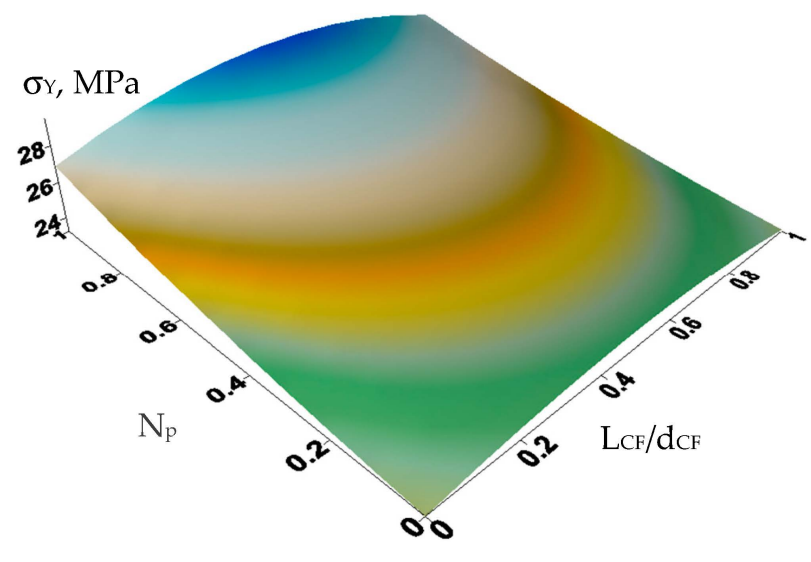

(e)

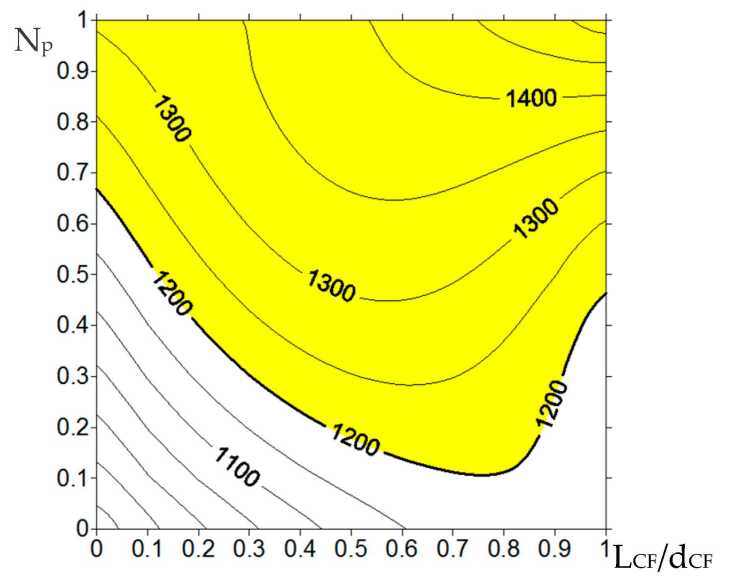

(b)

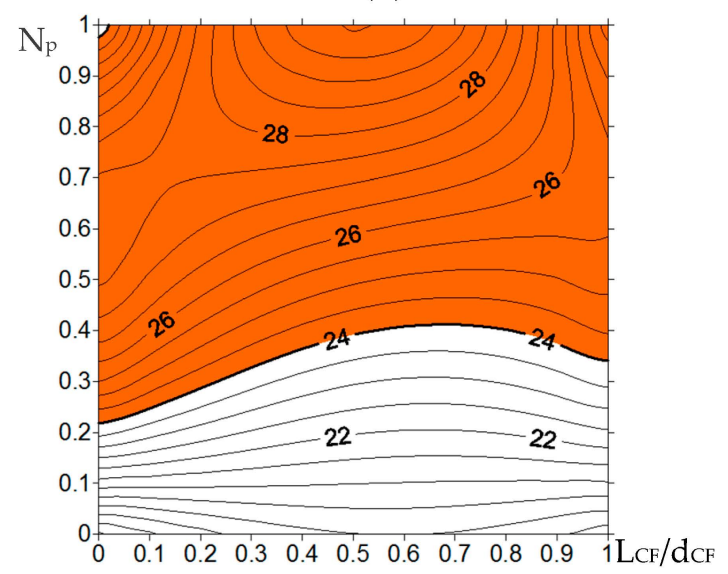

(d)

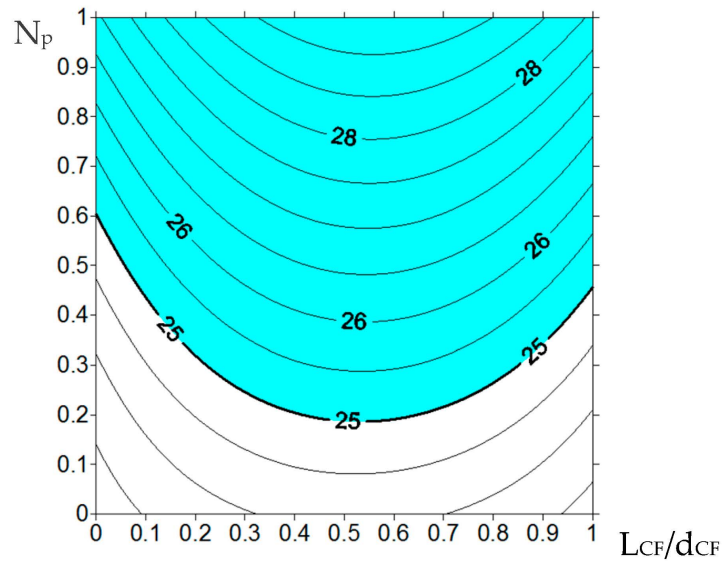

(f)

Figure 12. Cont. 


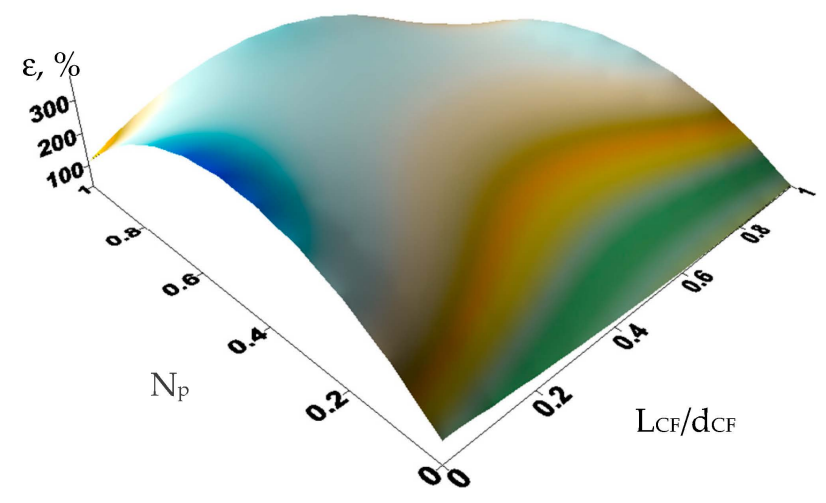

(g)

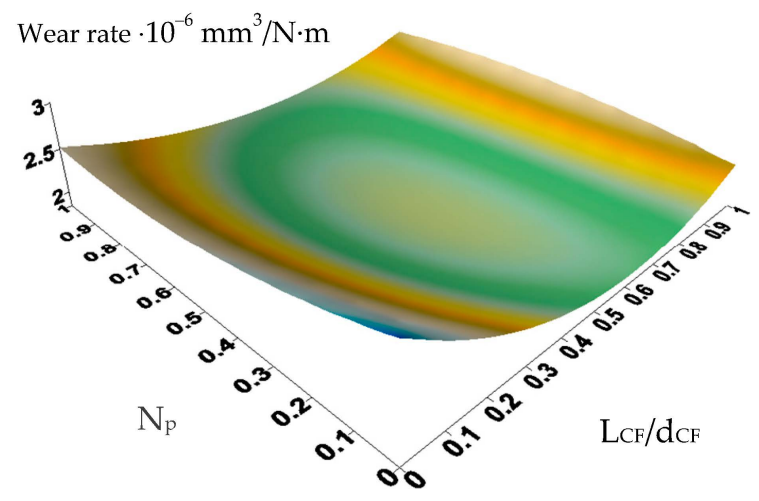

(i)

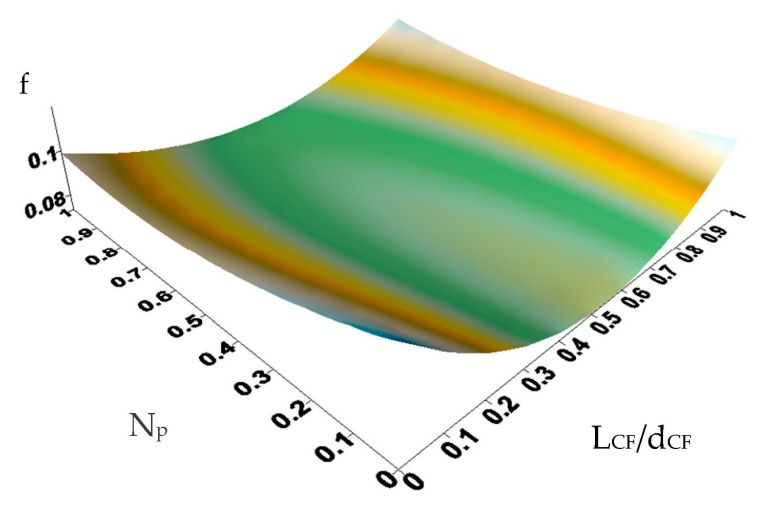

(k)

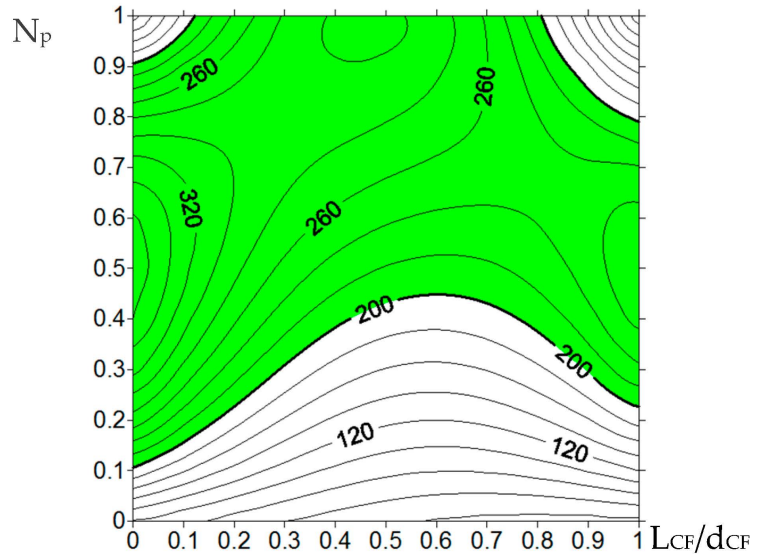

(h)

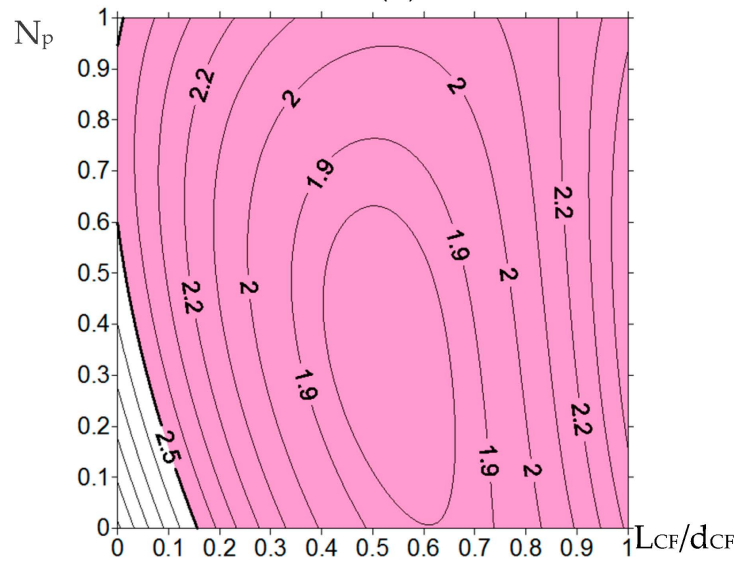

(j)

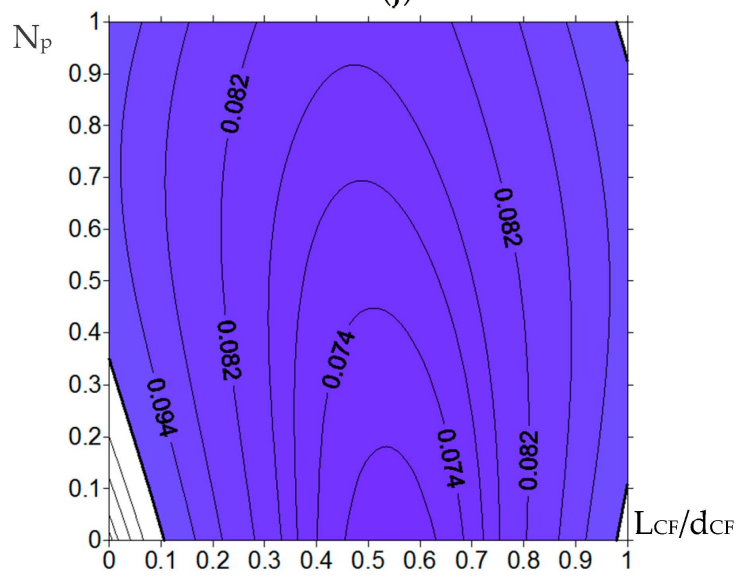

(1)

Figure 12. Cont. 


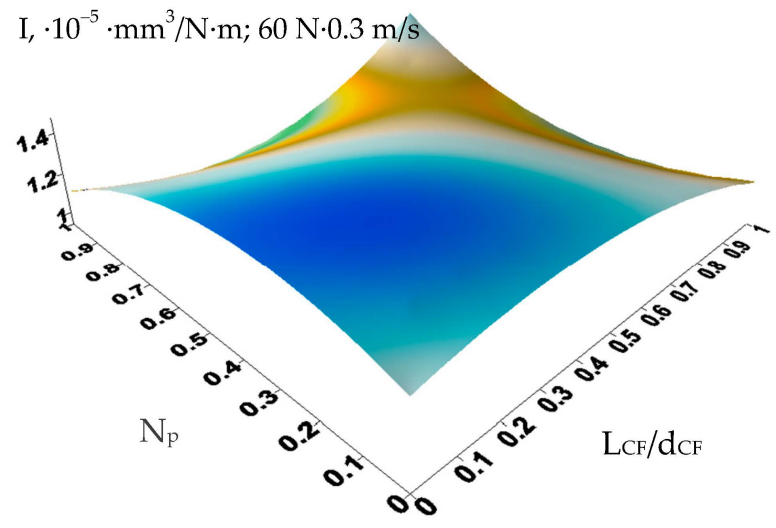

$(\mathbf{m})$

\section{I, $\cdot 10^{-5} \cdot \mathrm{mm}^{3} / \mathrm{N} \cdot \mathrm{m} ; 140 \mathrm{~N} \cdot 0.5 \cdot \mathrm{m} / \mathrm{s}$}

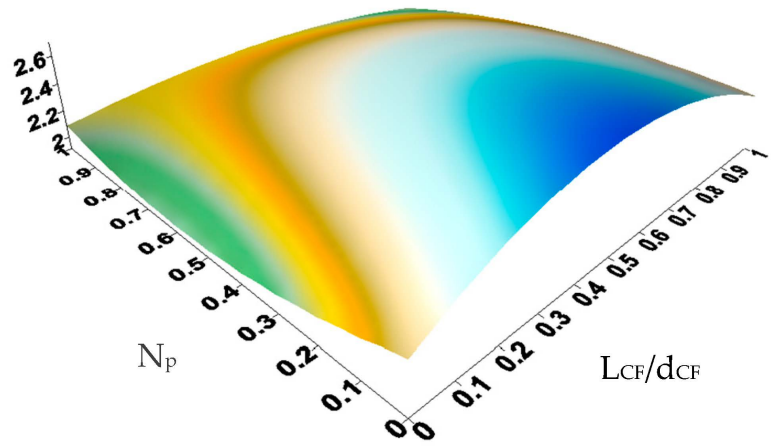

(o)

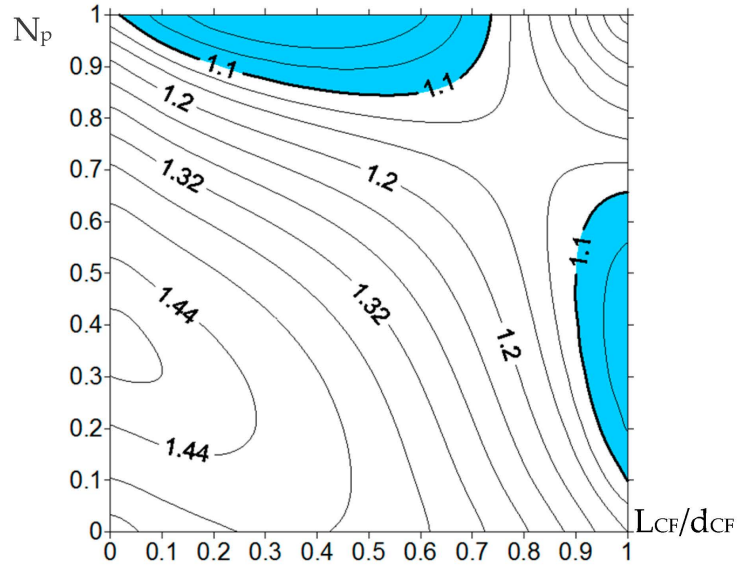

(n)

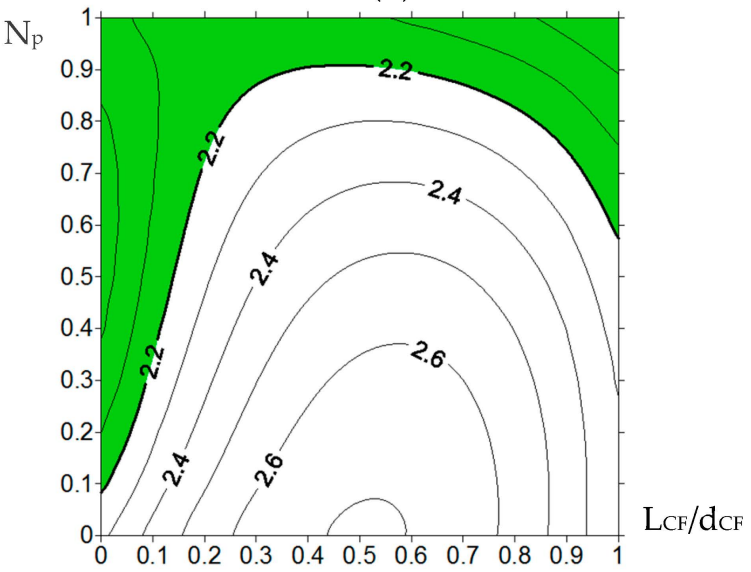

(p)

Figure 12. The functional properties of the UHMWPE-based composites vs. the number of processing passes in the extruder and the aspect ratio: $(\mathbf{a}, \mathbf{b})$ tensile Young's modulus $\mathrm{E}(\mathrm{MPa}) ;(\mathbf{c}, \mathbf{d})$ ultimate tensile strength $\sigma_{\mathrm{T}}(\mathrm{MPa}) ;(\mathbf{e}, \mathbf{f})$ yield strength $\sigma_{\mathrm{Y}}$ $(\mathrm{MPa}) ;(\mathbf{g}, \mathbf{h})$ elongation at break $\varepsilon(\%) ;(\mathbf{i}, \mathbf{j})$ wear rate I $\left(10^{-6} \cdot \mathrm{mm}^{3} / \mathrm{N} \cdot \mathrm{m}\right)$ (the 'ball-on-disk' scheme; the 'mild' tribological conditions); (k,l) the friction coefficient $\mathrm{f} ;(\mathbf{m}, \mathbf{n})$ wear rate $\mathrm{I} \cdot\left(10^{-5} \mathrm{~mm}^{3} / \mathrm{N} \cdot \mathrm{m}\right)$ (the 'block-on-ring' scheme; the 'mild' tribological conditions); (o,p) wear rate $\mathrm{I} \cdot\left(10^{-5} \mathrm{~mm}^{3} / \mathrm{N} \cdot \mathrm{m}\right)$ (the 'block-on-ring' scheme; the 'severe' tribological conditions).

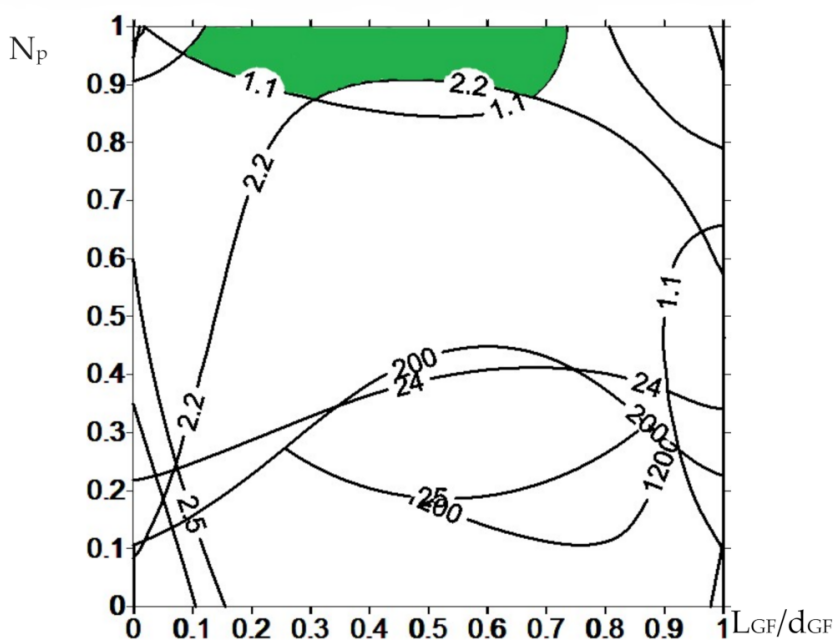

Figure 13. The area determining the number of processing passes and the aspect ratio of the glass filler required to obtain the UHMWPE-based composites with the predefined properties. 


\section{Conclusions}

Based on the obtained results, the following conclusions were drawn.

It was experimentally determined that loading UHMWPE with 17\% HDPE grafted with VTMS (trimethoxysilane) was able to bind $5 \%$ glass fillers of different aspect ratios, thereby determining the optimal mechanical and tribological properties of the composites. Further increasing the glass filler content resulted in the deterioration in their tribological characteristics due to insufficient adhesion of the extrudable matrix to the excessively loaded filler.

The multi-level approach was implemented to design the high-strength wear resistant 'UHMWPE+17\%HDPE-g-VTMS+12\%PP'-based composites using the computer-aided algorithms. This resulted in the determination of the main parameters that provided their predefined mechanical and tribological properties and enabled us to assess the possible load-speed conditions for their operations in friction units.

The uniform distribution of the fillers in the matrix, the nature of the formed supermolecular structure and, as a consequence, the mechanical and tribological properties of the composites were achieved by optimizing the values of the main control parameters (the number of processing passes in the extruder and the aspect ratio of the glass filler).

For the fabrication of the composites, the twin-screw extrusion method was recommended for roller guides, plate chains, conveyors, and pipes for pumping corrosive liquids as well as 3D-printing (FDM) for complex-shaped parts operated in high-loaded friction units under various tribological conditions.

Author Contributions: Methodology, D.G.B., Y.V.D., S.A.B.; validation, S.V.P., F.B. and L.A.K.; formal analysis, S.V.P., S.A.B.; investigation, S.V.P., D.G.B., Y.V.D.; data curation, F.B.; writing-original draft preparation, D.G.B., L.A.K.; writing-review and editing, S.V.P., D.G.B., F.B. and L.A.K. All authors have read and agreed to the published version of the manuscript.

Funding: The work was performed according to the Government research assignment for ISPMS SB RAS, project FWRW-2021-0010, and RFBR grants number 19-38-90106 and 20-58-00032 Bel_a. The work was also supported by the RF President Council Grant for the support of leading research schools NSh-2718.2020.8.

Institutional Review Board Statement: Not applicable.

Informed Consent Statement: Not applicable.

Data Availability Statement: The data presented in this study are available on request from the corresponding author.

Acknowledgments: The twin-screw compounding and FDM printing were carried out at the National Research Tomsk Polytechnic University within the framework of the Competitiveness Enhancement Program of Tomsk Polytechnic University.

Conflicts of Interest: The authors declare no conflict of interest. The founding sponsors had no role in the design of the study; in the collection, in the writing of the manuscript, and in the decision to publish the results.

\section{References}

1. Patil, N.A.; Njuguna, J.; Kandasubramanian, B. UHMWPE for Biomedical Applications: Performance and Functionalization. Eur. Polym. J. 2020, 125, 109529. [CrossRef]

2. Fang, L.M.; Leng, Y.; Gao, P. Effect of HA Content on Mechanical Properties of Hot Drawn HA/UHMWPE Nanocomposites for Bone Substitutes. Key Eng. Mater. 2007, 334, 701-704.

3. Kurtz, S.M. Chapter 2-From ethylene gas to UHMWPE component: The process of producing orthopedic implants. In UHMWPE Biomaterials Handbook, 2nd ed.; Kurtz, S.M., Ed.; Academic Press: Boston, MA, USA, 2009; pp. 7-19.

4. Sánchez-Sánchez, X.; Hernández-Avila, M.; Elizalde, L.E.; Martínez, O.; Ferrer, I.; Elías-Zuñiga, A. Micro injection molding processing of UHMWPE using ultrasonic vibration energy. Mater. Des. 2017, 132, 1-12. [CrossRef]

5. Wahyudi, M.; Putra, Y.E.; Arrohman, S.; Jamari, J.; Ismail, R. A comparison between mechanical properties of UHMWPE from ram extrusion process and UHMWPE from compression molding process for a hip joint liner. IOP Conf. Ser. Mater. Sci. Eng. 2018, 432, 012007. [CrossRef] 
6. Xie, M.; Li, H. Mechanical properties of an ultrahigh-molecular-weight polyethylene/polypropylene blend containing poly(ethylene glycol) additives. J. Appl. Polym. Sci. 2008, 108, 3148-3153. [CrossRef]

7. Liu, G.; Chen, Y.; Li, H. Study on Processing of Ultrahigh Molecular Weight Polyethylene/Polypropylene Blends: Capillary Flow Properties and Microstructure. Inc. J. Appl. Polym. Sci. 2004, 92, 3894-3900. [CrossRef]

8. Lee, E.M.; Oh, Y.S.; Ha, H.S.; Kim, B.K. Rheological properties of UHMWPE/iPP blends. Polym. Adv. Technol. 2009, 20, 1121-1126. [CrossRef]

9. Zhang, X.; Tan, Y.; Li, Y.; Zhang, G. Effect of OMMT on microstructure, crystallisation and rheological behaviour of UHMWPE/PP nanocomposites under elongation flow. Plast. Rubber Compos. 2018, 47, 315-323. [CrossRef]

10. Avila-Orta, C.A.; Burger, C.; Somani, R.; Yang, L.; Marom, G.; Medellin-Rodriguez, F.J.; Hsiao, B.S. Shear-induced crystallization of isotactic polypropylene within the oriented scaffold of noncrystalline ultrahigh molecular weight polyethylene. Polymer 2005, 46, 8859-8871. [CrossRef]

11. Lee, E.M.; Jeong, H.M.; Kim, B.K. Mechanical, Thermal, and Surface Properties of Ultrahigh Molecular Weight Polyethylene/Polypropylene Blends. J. Macromol. Sci. Part B Phys. 2010, 49, 854-863. [CrossRef]

12. Xie, M.; Li, H. Viscosity reduction and disentanglement in ultrahigh molecular weight polyethylene melt: Effect of blending with polypropylene and poly (ethylene glycol). Eur. Polym. J. 2007, 43, 3480-3487. [CrossRef]

13. Gai, J.G.; Li, H.L.; Schrauwen, C.; Hu, G.H. Dissipative particle dynamics study on the phase morphologies of the ultrahigh molecular weight polyethylene/polypropylene/poly(ethylene glycol) blends. Polymer 2009, 50, 336-346. [CrossRef]

14. Xie, M.; Chen, J.; Li, H.; Li, M. Influence of poly (ethylene glycol)-containing additives on the sliding wear of ultrahigh molecular weight polyethylene/polypropylene blend. Wear 2010, 268, 730-736. [CrossRef]

15. He, S.; He, H.; Li, Y.; Wang, D. Effects of maleic anhydride grafted polyethylene on rheological, thermal, and mechanical properties of ultra high molecular weight polyethylene/poly(ethylene glycol) blends. J. Appl. Polym. Sci. 2015, $132,42701$. [CrossRef]

16. Chen, J.; Yang, W.; Yu, G.; Wang, M.; Ni, H.; Shen, K. Continuous extrusion and tensile strength of self-reinforced HDPE/UHMWPE sheet. J. Mater. Process. Technol. 2008, 202, 165-169. [CrossRef]

17. Bretas, R.E.S.; Granado, C. Simulation of the extrusion of HDPE and HDPE/UHMWPE blends. Eur. Polym. J. 1993, 29, 769-772. [CrossRef]

18. Lim, K.L.K.; Ishak, Z.A.M.; Ishiaku, U.S.; Fuad, A.M.Y.; Yusof, A.H.; Czigany, T.; Pukanszky, B.; Ogunniyi, D.S. High-density polyethylene/ultrahigh-molecular-weight polyethylene blend. I. The processing, thermal, and mechanical properties. J. Appl. Polym. Sci. 2005, 97, 413-425. [CrossRef]

19. Liu, L.; Wang, F.; Xue, P.; Wang, S. Influence of interfacial condition on rheological instability behavior of UHMWPE/HDPE/nano$\mathrm{SiO} 2$ blends in capillary extrusion. Rheol. Acta 2019, 58, 183-192. [CrossRef]

20. Kuang, T.; Chang, L.; Fu, D.; Yang, J.; Zhong, M.; Chen, F.; Peng, X. Improved crystallizability and processability of ultra high molecular weight polyethylene modified by poly(amido amine) dendrimers. Polym. Eng. Sci. 2016, 57, 153-160. [CrossRef]

21. Ren, X.; Wang, X.Q.; Sui, G.; Zhong, W.H.; Fuqua, M.A.; Ulven, C.A. Effects of carbon nanofibers on crystalline structures and properties of ultrahigh molecular weight polyethylene blend fabricated using twin-screw extrusion. J. Appl. Polym. Sci. 2007, 107, 2837-2845. [CrossRef]

22. Danilova, S.N.; Yarusova, S.B.; Kulchin, Y.N.; Zhevtun, I.G.; Buravlev, I.Y.; Okhlopkova, A.A.; Gordienko, P.S.; Subbotin, E.P. UHMWPE $/ \mathrm{CaSiO}_{3}$ Nanocomposite: Mechanical and Tribological Properties. Polymers 2021, 13, 570. [CrossRef]

23. Amza, C.G.; Zapciu, A.; Eypórsdóttir, A.; Björnsdóttir, A.; Borg, J. Embedding Ultra-High-Molecular-Weight Polyethylene Fibers in 3D-Printed Polylactic Acid (PLA) Parts. Polymers 2019, 11, 1825. [CrossRef] [PubMed]

24. Yang, G.; Park, M.; Park, S.J. Recent progresses of fabrication and characterization of fibers-reinforced composites: A review. Compos. Commun. 2019, 14, 34-42. [CrossRef]

25. Wang, Y.; Yin, Z. Tribological properties of ultrahigh-molecular-weight polyethylene (UHMWPE) composites reinforced with different contents of glass and carbon fibers. Ind. Lubr. Tribol. 2019, 71, 22-30. [CrossRef]

26. Yin, X.; Yin, Y.; Cheng, D.; Feng, Y.; Zhang, G.; Wen, J. In-Situ Bubble Stretching Assisted Melt Extrusion for the Preparation of HDPE/UHMWPE/CF Composites. Polymers 2019, 11, 2054. [CrossRef] [PubMed]

27. Chukov, D.I.; Stepashkin, A.A.; Maksimkin, A.V.; Tcherdyntsev, V.V.; Kaloshkin, S.D.; Kuskov, K.V.; Bugakov, V.I. Investigation of structure, mechanical and tribological properties of short carbon fiber reinforced UHMWPE-matrix composites. Compos. Part $B$ Eng. 2015, 76, 79-88. [CrossRef]

28. Wang, Y.; Yin, Z.; Li, H.; Gao, G.; Zhang, X. Friction and wear characteristics of ultrahigh molecular weight polyethylene (UHMWPE) composites containing glass fibers and carbon fibers under dry and water-lubricated conditions. Wear 2017, 380, 42-51. [CrossRef]

29. Satapathy, S.; Jose, J.; Nag, A.; Nando, G.B. Short Glass Fiber Filled Waste Plastic (PE) Composites: Studies on Thermal and Mechanical Properties. Prog. Rubber Plast. Recycl. Technol. 2008, 24, 199-218. [CrossRef]

30. AlMaadeed, M.A.; Ouederni, M.; Noorunnisa Khanam, P. Effect of chain structure on the properties of Glass fibre/polyethylene composites. Mater. Des. 2013, 47, 725-730. [CrossRef]

31. Alqaflah, A.M.; Alotaibi, M.L.; Aldossery, J.N.; Alghamdi, M.S.; Alsewailem, F.D. Preparation and characterization of glass fiber-reinforced polyethylene terephthalate/linear low density polyethylene (GF-PET/LLDPE) composites. Polym. Adv. Technol. 2017, 29, 52-60. [CrossRef] 
32. Lins, S.A.B.; Rocha, M.C.G.; D' Almeida, J.R.M. Mechanical and thermal properties of high-density polyethylene/alumina/glass fiber hybrid composites. J. Thermoplast. Compos. Mater. 2018, 32, 1566-1581. [CrossRef]

33. Tselios, C.; Bikiaris, D.; Savidis, P.; Panayiotou, C.; Larena, A. Glass-fiber reinforcement of in situ compatibilized polypropylene/polyethylene blends. J. Mater. Sci. 1999, 34, 385-394. [CrossRef]

34. Panin, S.V.; Kornienko, L.A.; Huang, Q.; Buslovich, D.G.; Bochkareva, S.A.; Alexenko, V.O.; Panov, I.L.; Berto, F. Effect of Adhesion on Mechanical and Tribological Properties of Glass Fiber Composites, Based on Ultra-High Molecular Weight Polyethylene Powders with Various Initial Particle Sizes. Materials 2020, 13, 1602. [CrossRef]

35. Fabris, F.W.; Cardozo, N.S.M.; Mauler, R.S.; Nachtigall, S.M.B. Improving the properties of LDPE/glass fiber composites with silanized-LDPE. Polym. Compos. 2009, 30, 872-879. [CrossRef]

36. Chen, S.; Li, J.; Jin, Y.; Xiao, J.; Khosla, T.; Hua, M.; Jia, D.; Duan, H. Fabrication of Polyimide-Modified UHMWPE Composites and Enhancement Effect on Tribological Properties. Polym. Plast. Technol. Eng. 2017, 57, 700-707. [CrossRef]

37. Xing, J.; Ni, Q.-Q.; Deng, B.; Liu, Q. Morphology and properties of polyphenylene sulfide (PPS)/polyvinylidene fluoride (PVDF) polymer alloys by melt blending. Compos. Sci. Technol. 2016, 134, 184-190. [CrossRef]

38. Dontsov, Y.V.; Panin, S.V.; Buslovich, D.G.; Berto, F. Taguchi Optimization of Parameters for Feedstock Fabrication and FDM Manufacturing of Wear-Resistant UHMWPE-Based Composites. Materials 2020, 13, 2718. [CrossRef]

39. Cheng, B.; Duan, H.; Chen, S.; Shang, H.; Li, J.; Shao, T. Phase morphology and tribological properties of PI/UHMWPE blend composites. Polymer 2020, 202, 122658. [CrossRef]

40. Chen, S.; Li, J.; Wei, L.; Jin, Y.; Khosla, T.; Xiao, J.; Cheng, B.; Duan, H. A molecular modeling study for miscibility of polyimide/polythene mixing systems with/without compatibilizer. J. Polym. Eng. 2018, 38, 891-898. [CrossRef]

41. Guo, Z.; Xu, R.; Xue, P. Study on Preparation of Ultra-High-Molecular-Weight Polyethylene Pipe of Good Thermal-Mechanical Properties Modified with Organo-Montmorillonite by Screw Extrusion. Materials 2020, 13, 3342. [CrossRef]

42. UHMW Guide Rail Shields, Catalog of Misumi Group Inc. Available online: https://uk.misumi-ec.com/vona2/detail/11030014 0370/\# (accessed on 19 February 2021).

43. UHMWPE Guide Rail Upe Linear Guide, Guangzhou Engineering Plastics Industries (Group) Co. Available online: https: //www.gzenqi.com/plastic-guide/uhmwpe_linear_guide_rail.html (accessed on 19 February 2021).

44. Polyslick UHMW, Catalog of Polymer Industries. Available online: http://polymerindustries.com/wp/uhmwpe (accessed on 19 February 2021).

45. ASTM International. Standard Test Methods for Density and Specific Gravity (Relative Density) of Plastics by Displacement, ASTM D792-20; ASTM International: West Conshohocken, PA, USA, 2020.

46. ASTM International. Standard Test Method for Tensile Properties of Plastics, ASTM D638-14; ASTM International: West Conshohocken, PA, USA, 2014.

47. ASTM International. Standard Test Method for Static and Kinetic Coefficients of Friction of Plastic Film and Sheeting, ASTM D1894-14; ASTM International: West Conshohocken, PA, USA, 2014.

48. ASTM International. Standard Specification for Ultra-High-Molecular-Weight Polyethylene Molding and Extrusion Materials, ASTM D4020-18; ASTM International: West Conshohocken, PA, USA, 2018.

49. ASTM International. Standard Test Method for Rubber Property—Durometer Hardness, ASTM D2240-15e1; ASTM International: West Conshohocken, PA, USA, 2015.

50. Machined UHMW Parts, Catalog of Tangyin Dingyuan Engineering Plastics Co., Ltd. Available online: http://www.dyuhmw. com/uhmw-polyethylene/ (accessed on 19 February 2021).

51. Polystone ${ }^{\circledR}$ M natural (PE-UHMW/PE1000), Catalog of Röchling Engineering Plastics. Available online: https://www.roechlingindustrial.com/materials/thermoplastics/detail/polystone-m-natural-72 (accessed on 19 February 2021).

52. International Standards Organization for Standardization (ISO). International Standard, Plastics-Methods for Determining the Density of Non-Cellular Plastics, International Standard ISO 1183; ISO: Geneva, Switzerland, 2019.

53. International Standards Organization for Standardization (ISO). International Standard, Plastics-Determination of Water Absorption, International Standard ISO 62; ISO: Geneva, Switzerland, 2008.

54. International Standards Organization for Standardization (ISO). International Standard, Plastics—Determination of Tensile Properties ISO 527; ISO: Geneva, Switzerland, 2019.

55. International Standards Organization for Standardization (ISO). International Standard, Plastics—Determination of Charpy Impact Properties, International Standard ISO 179; ISO: Geneva, Switzerland, 2020.

56. International Standards Organization for Standardization (ISO). Plastics and Ebonite-Determination of Indentation Hardness by Means of a Durometer (Shore Hardness), International Standard ISO 868; ISO: Geneva, Switzerland, 2003.

57. Product Data Sheets TIVAR ${ }^{\circledR}$ 1000, Catalog of Mitsubishi Chemical Advanced Materials. Available online: https: / / media.mcam.com/fileadmin/quadrant/documents/QEPP/EU/Product_Data_Sheets_PDF/PE/MCAM-TIVAR-PEUHMW-RUS-PDS-070720.pdf?_ga=2.82581854.939953073.1601951916-391704620.1601951916 (accessed on 19 February 2021).

58. International Standards Organization for Standardization (ISO). International Standard, Plain Bearings-Testing of the Tribological Behaviour of Bearing Materials, International Standard ISO 7148; ISO: Geneva, Switzerland, 2012.

59. ASTM International. Standard Test Methods for Determining the Izod Pendulum Impact Resistance of Plastics, ASTM D256-10; ASTM International: West Conshohocken, PA, USA, 2018. 
60. Werkstoff' ${ }^{\prime}{ }^{\circledR}$ PE 1000 'S Catalog of Murtfeldt Kunststoffe GmbH \& Co. Available online: https:/ / www.murtfeldt.de/produkte/ kunststoffe/werkstoff-s-gruppe/original-werkstoff-s-gruen-natur/ (accessed on 19 February 2021).

61. International Standards Organization for Standardization (ISO). International Standard, Plastics. Determination of Hardness. Ball Indentation Method, International Standard ISO 2039; ISO: Geneva, Switzerland, 2001.

62. Bochkareva, S.A.; Grishaeva, N.Y.; Lyukshin, B.A.; Lyukshin, P.A.; Matolygina, N.Y.; Panin, S.V.; Reutov, Y.A. A unified approach to determining the effective physicomechanical characteristics of filled polymer composites based on variational principles. Mech. Compos. Mater. 2019, 54, 775-788. [CrossRef]

63. Panin, S.V.; Bochkareva, S.A.; Buslovich, D.G.; Kornienko, L.A.; Lyukshin, B.A.; Panov, I.L.; Shilko, S.V. Computer aided design of extrudable polymer-polymer UHMWPE composites with specified antifriction and mechanical properties. J. Frict. Wear. 2019, 40, 661-672. [CrossRef]

64. Bergh, J.; Lofstrom, J. Interpolation Spaces; Grundlehren der Mathematischen Wissenschaften Book Series; Springer: Berlin/Heidelberg, Germany, 1976; p. 175. 